\title{
Common Risk Factors in Equity Markets
}

\author{
Victoria Atanasov
}

Faculty of Economics and Business Administration, VU University Amsterdam, and Tinbergen Institute. 
Tinbergen Institute is the graduate school and research institute in economics of Erasmus University Rotterdam, the University of Amsterdam and VU University Amsterdam.

More TI discussion papers can be downloaded at http://www.tinbergen.nl

Tinbergen Institute has two locations:

Tinbergen Institute Amsterdam

Gustav Mahlerplein 117

1082 MS Amsterdam

The Netherlands

Tel.: +31(0)205251600

Tinbergen Institute Rotterdam

Burg. Oudlaan 50

3062 PA Rotterdam

The Netherlands

Tel.: +31(0)10 4088900

Fax: $+31(0) 104089031$

Duisenberg school of finance is a collaboration of the Dutch financial sector and universities, with the ambition to support innovative research and offer top quality academic education in core areas of finance.

DSF research papers can be downloaded at: http://www.dsf.nl/

Duisenberg school of finance

Gustav Mahlerplein 117

1082 MS Amsterdam

The Netherlands

Tel.: +31(0)20 5258579 


\title{
Common Risk Factors in Equity Markets*
}

\author{
Victoria Atanasov
}

First draft: December 15, 2013

This version: May 26, 2014

*Victoria Atanasov, VU University Amsterdam, FEWEB, De Boelelaan 1105, 1081 HV, Amsterdam, Netherlands, tel +31 2059 83099, v.atanasov@ vu.nl and Tinbergen Institute. I would like to thank Stefano Giglio, Thomas Nitschka and the participants at the Banca d'Italia-ECB 2013 Workshop on Financial Determinants of Exchange Rates for helpful comments. Any errors and omissions are my own responsibility. 


\title{
Common Risk Factors in Equity Markets
}

\begin{abstract}
Empirical measures of world consumption growth risk have failed to rationalize the cross-section of country equity returns. We propose a new factor, termed "the global consumption factor", to explain the patterns in risk premiums on international equity markets. We identify this factor as the difference between the return on a portfolio of equity market indices with high consumption growth rates and the return on a portfolio of equity market indices with low consumption growth rates. We show that the global consumption factor accounts for about $70 \%$ of the cross-sectional variation in equity returns from 47 developed and emerging market countries over a four-decade period. Our risk factor reflects changes in the cross-country consumption dispersion and commands a significant premium to compensate investors for taking on common macroeconomic risks. Empirically, we find that high consumption growth economies have considerably higher consumption dispersion risk than low consumption growth economies, and this can explain their higher average returns.
\end{abstract}

JEL: G11; G12

Keywords: stock returns, asset pricing, macroeconomic risks, consumption dispersion 


\section{Introduction}

If international markets are perfectly integrated and investors are similar in their consumption patterns and investment opportunity sets, then a single world consumption risk factor should explain the cross-section of global asset returns. This is the key insight of the canonical international consumption capital asset pricing model (CAPM) in Stulz (1981). Contrary to the prediction of this model, there exists no conclusive empirical evidence that international equity premiums are determined by the asset returns' sensitivities to fluctuations in the world consumption growth risk. ${ }^{1}$ The contribution of this paper is to show that a single risk factor, termed "the global consumption factor", accounts for about $70 \%$ of the cross-sectional variation in equity returns of 47 developed and emerging market countries over the period from January 1970 to December 2012. If the global consumption factor is a systematic risk factor in international equity markets, the finance theory predicts that markets with different sensitivities to this factor should have different excess returns.

We identify our global consumption factor in the data by building equity portfolios sorted by the countries' year-over-year consumption growth rates based upon the fourth quarter. Portfolios are rebalanced at the end of each December such that the first portfolio always contains the lowest long-run consumption growth economies, while the last the highest. We compute the return on the global consumption factor as the spread in returns between baskets of high and low long-run consumption growth portfolios, similar to the return on a zero-cost investment strategy which is long in high long-run consumption growth markets and short in low long-run consumption growth markets. We label this excess

\footnotetext{
${ }^{1}$ See e.g. Wheatley (1988), Cumby (1990), Karolyi and Stulz (2003) for a survey, Li and Zhong (2005), Darrat et al. (2011), and, most recently, Rangvid et al. (2012).
} 
return the global consumption factor, or " $H M L$ " factor, for high minus low consumption growth markets. This excess return is highly significant, economically of the order of 90 basis points per month and has increased in recent years.

Our empirical exercise is motivated by Jagannathan and Wang (2007) who show that when consumption betas are computed using so-called "discretionary" consumption growth measured as fourth-quarter-over-fourth-quarter consumption changes, the domestic consumption CAPM becomes a powerful tool in explaining the cross-section of US stock returns. Guided by this insight and the literature on long-run consumption risks (e.g. Bansal and Yaron (2004), Parker and Julliard (2005), and Rangvid et al. (2012))2 we test whether the sensitivity of excess returns to the global consumption factor can rationalize the returns to equity portfolios in a standard, linear asset pricing framework. We find almost a monotonic relation between portfolios' $H M L$ exposures and their average excess returns: High consumption growth markets load positively on $H M L$, while low consumption growth markets load negatively on $H M L$. Differences in these loadings are tightly linked to differences in average returns across assets, and this implies that investors with access to international markets are compensated for exposure to common macroeconomic risks. Our results are robust over time and across assets and are invariant to the estimation methodology and index return computation methods.

We also study the relation between risk loadings and average returns on portfolios sorted on the countries' realized $H M L$ betas. To obtain time-varying risk loadings, we follow

\footnotetext{
${ }^{2}$ By exploiting the fact that consumption is slow to adjust and it is its slow-moving low-frequency component which is informative about changes in market wealth, this literature responds to empirical deficits of a standard consumption CAPM by Lucas (1978) and Breeden (1979) in which asset risk is approximated by contemporaneous covariance of its returns and quarterly consumption growth (e.g. Hansen and Singleton (1982), Mankiw and Shapiro (1986), Breeden et al. (1989), Campbell (1996), Cochrane (1996), and Lettau and Ludvigson (2001)).
} 
Ang et al. (2006) and run rolling window overlapping time-series regressions of individual equity index returns on $H M L .^{3}$ Evidence from both Fama and MacBeth (1973) regressions and portfolio sorts suggests that $H M L$ betas do convey important information about the riskiness of assets and go a long way toward explaining their average returns. Our results remain valid in a subsample of developed countries and hold true for alternative rolling window lengths, and for both returns denominated in USD and national currency units.

Several recent studies rely on portfolio formation to obtain sharper estimates of the riskreturn trade-off. Arguably, creating portfolios diminishes idiosyncratic variation, mitigates the error-in-variables bias, and promises a more precise estimation of risk premiums. For instance, Lustig and Verdelhan (2007), Lustig et al. (2011), and Menkhoff et al. (2012) sort currencies into portfolios to show that a risk-based explanation applies to exchange rate determination. Earlier literature has used financial characteristics such as firm's size, valuation ratios, or past performance to investigate the risk-return profile of stocks (e.g. Black et al. (1972), Fama and MacBeth (1973), and Fama (1976)). While these studies provide valuable insights about the properties of returns, they cannot directly address the question as to what fundamental economic sources drive equity returns. ${ }^{4}$ Our main contribution to this literature is to consider a theoretically motivated risk factor-our global consumption risk factor-and show that it plays a major role in determining equity risk premiums.

\footnotetext{
${ }^{3}$ In one of our robustness checks, we also examine non-overlapping sample periods.

${ }^{4}$ Several seminal papers address this question by sorting currencies according to countries' macro fundamentals such as consumption growth, GDP, industrial production, and net foreign asset positions (e.g. Hoffmann and Suter (2013), Menkhoff et al. (2013), and Della Corte et al. (2014)). However, none of these studies examines global equity markets.
} 
Our work is closely related to Lustig et al. (2011) who employ a data-driven approach arising from the arbitrage pricing theory (APT) of Ross (1976) to identify two common risk factors in currency returns: the average currency excess return of a set of currencies against the USD, termed "the dollar factor" $(R X)$, and a so-called "carry trade risk factor" in currencies which is equivalent to a high-minus-low $\left(H M L_{F X}\right)$ strategy that buys currencies with high interest rates and sells currencies with low interest rates. In contrast, we focus on international equity markets and show that cross-sectional differentials in equity returns can be understood by relating them to two risk factors in equity returns: the $R X$ factor which is essentially the market return on a well-diversified portfolio of international equities, our global consumption factor which is similar to a high-minus-low $(H M L)$ strategy that buys equities of countries with high consumption growth rates and sells equities of countries with low consumption growth rates. We find that the latter factor is the pervasive risk factor in the cross-section of equity returns and that it can explain a large part of price changes in equity markets across borders.

To understand the economic origins of the global consumption factor, we take a closer look at the relationship between the cross-sectional distribution of country-specific consumption growth rates and the expected equity premiums. To the extent that there is sufficient heterogeneity in countries' consumption patterns, for example because of the presence of uninsurable idiosyncratic shocks, higher moments of and, in particular, the cross-sectional multi-country consumption dispersion may be of critical importance to explain price changes. While considerable theoretical (e.g. Telmer (1993), Constantinides and Duffie (1996), Heaton and Lucas (1996), and Gomes and Michaelides (2008)) and empirical (e.g. Brav et al. (2002), Cogley (2002), and Jacobs and Wang (2004)) research 
has examined the role of market incompleteness and imperfect consumption risk sharing across individuals for domestic stock returns, the question of how cross-country consumption dispersion affects the time-varying global risk premiums has received less attention. One known exception is Sarkissian (2003) who highlights the importance of incomplete international consumption risk sharing for currency pricing. ${ }^{5}$

We show that heterogeneity in exposure to unexpected changes in the cross-country consumption dispersion can rationalize a substantial part of the explanatory power of the global consumption risk factor in equities. In accordance with the finance theory, our results indicate that equity return is higher the more negatively correlated it is with innovations in consumption dispersion. The latter is strongly countercyclical—high in recessions and low in booms - and this feature of the data turns out helpful for equity pricing. Empirically, we find that high consumption growth economies have considerably higher consumption dispersion risk than low consumption growth economies, and this can explain their higher average returns. Importantly, the price of dispersion risk is negative, consistent with the view that assets which perform poorly in uncertain aggregate times require higher expected returns.

The difference between our results and the results of past studies is that the past literature either does not examine the consumption dispersion in the international setup, or does not investigate the asset pricing implications for equity markets. For example, Sarkissian (2003) studies the impact of the cross-country variance of consumption growth rates on

\footnotetext{
${ }^{5}$ Gomes et al. (2009) test the cross-sectional implications of "keeping-up-with-the Joneses" preferences with idiosyncratic shocks in an international setting. Li and Zhong (2009) use a consumption-based framework with idiosyncratic, country-specific consumption risk and country-specific habit formation to investigate the cross-section of currency and international equity premiums. Li (2010) also studies an international version of consumption CAPM with heterogeneity but he does not investigate the crosssectional implications of the model.
} 
cross-sectional differences in currency returns, while Jacobs and Wang (2004) investigate the importance of the cross-sectional variance of micro-level household consumption growth on US stock returns. While we also study the effect of time-varying consumption dispersion, we focus on international equity markets.

In a recent article, Hoffmann and Suter (2013) sort currencies into portfolios by country's past long-run consumption growth to show that the excess return of the-highest-over-thelowest consumption growth portfolios can price the cross-section of currency returns from 1990 to 2010. Our paper differs substantially from that article. First, our focus is on international equity rather than foreign exchange markets. Second, data availability allows us to consider a longer time period and a broader cross-section of countries. Third, we sort on the fourth-quarter-over-fourth-quarter contemporaneous consumption changes as opposed to past overlapping annual consumption growth. Fourth, we show that our global consumption factor is related to cross-country consumption dispersion, while Hoffmann and Suter (2013) interpret their findings in a framework of an asset pricing model with habit formation.

To summarize, our study relates to two strands of literature. First, we show that an empirical approximation of the APT with two risk factors-the market returns and the global consumption risk factor-can explain a large part of the variation in expected excess returns on 47 developed and emerging market equity indices. In this respect, we reinforce a risk-based view of equity premium formation in equity markets around the world. Second, we show that time-variation in our global consumption factor reflects unexpected changes in the cross-country consumption dispersion risk. This finding 
extends a growing literature which highlights the importance of imperfect consumption risk sharing for international asset pricing.

The remainder of the article is organized as follows. Section 2 describes the data and construction of equity portfolios and provides descriptive statistics. Section 3 shows that global consumption factor is key to explain the cross-section of equity returns. Section 4 relates the global consumption factor to cross-country consumption dispersion, and Section 5 concludes.

\section{Data and Equity Portfolios}

This section describes the macroeconomic data employed in the empirical analysis, the construction of equity portfolios and our proxies for common risk factors. It also summarizes the main properties of the international equity portfolios.

\subsection{International Macroeconomic Data}

Our sample comprises at most 47 countries: Australia, Austria, Belgium, Brazil, Canada, Chile, China, Colombia, Czech Republic, Denmark, Egypt, Estonia, Finland, France, Germany, Greece, Hong Kong, Hungary, India, Indonesia, Ireland, Israel, Italy, Japan, Korea, Malaysia, Mexico, Morocco, Netherlands, New Zealand, Norway, Peru, Philippines, Poland, Portugal, Russia, Singapore, Slovenia, South Africa, Spain, Sweden, Switzerland, Taiwan, Thailand, Turkey, United Kingdom, and United States. As a robustness check, we also study a smaller dataset that contains at most 25 developed countries: Australia, Austria, Belgium, Canada, Denmark, Estonia, Finland, France, Germany, Hong Kong, Ireland, Israel, Italy, Japan, Netherlands, New Zealand, Norway, Portugal, Singapore, Slovenia, Spain, Sweden, Switzerland, United Kingdom, and United 
States. The definition of developed countries follows the MSCI country classification. ${ }^{6}$ We first focus the description of our results on the large sample of all countries, but we present all of the results on both samples.

The international private consumption data are collected from different sources. Most series come from the national accounts downloaded from OECD.Stat. Consumption data for Colombia, Egypt, Malaysia, Morocco, Peru, Philippines, Singapore, and Thailand are from the IMF International Financial Statistics. Consumption data for Colombia are from the National Administrative Department of Statistics of Colombia accessed via Datastream. Consumption data for Hong Kong are obtained from the Hong Kong Census and Statistics Department. Consumption data for Taiwan are from the national accounts as published by the Statistical Bureau of Taiwan.

Population numbers for most countries are obtained from OECD.Stat. Population data for Colombia, Egypt, India, Indonesia, Malaysia, Morocco, Peru, Philippines, and Thailand are from the IMF International Financial Statistics. Population data for China are from the World Bank Development Indicators. Population series for Hong Kong are from the Demographic Statistics Section of the Census and Statistics Department of Hong Kong. Population data for Singapore are from the Singapore Department of Statistics. Population figures for Taiwan are from the Federal Reserve Economic Data (FRED) of St. Louis Fed.

Series available in annual frequency were interpolated to quarterly. Since we focus on a US investor who invests in international equity indices, we work with household

\footnotetext{
${ }^{6}$ Estonia and Slovenia are classified as frontier markets according to the MSCI but belong to the developed economies according to the UN and IMF, and to the high-income economies according to the World Bank. In the recent MSCI classification, Greece has been shifted from developed to emerging markets and Morocco has been reallocated from emerging to frontier markets.
} 
consumption expenditures denominated or converted in USD. ${ }^{7}$ Nominal series are converted to real by deflating the original series with the consumer price index (CPI). Many of the time series taken from the above mentioned sources are already seasonally adjusted. We adjust the remaining time series with seasonal fluctuations by using CensusX12. We construct log real per capita year-over-year consumption growth rates based upon the fourth quarter following Jagannathan and Wang (2007). To match the available international financial data, we calculate consumption growth rates from the fourth quarter of 1970 to the fourth quarter of 2012.

\subsection{MSCI Equity Indices}

For our benchmark tests, we use the standard MSCI equity index returns for developed and emerging markets freely available on http://www.msci.com. ${ }^{8}$ The MSCI equity indices are widely used as test assets in international finance and serve as the basis for a large number of traded funds by practitioners. This data base aims to cover about $80 \%$ of the market capitalization in the respective country and has the advantage of high quality and accuracy arising from the consistent methodology over time and regular market classification maintenance. Our monthly data set for MSCI equity returns covers the longest available sample period from January 1970 to December 2012. For robustness purposes, we repeat our tests with different MSCI index variants based on alternative size classifications and return computation methods. For most developed markets, the monthly MSCI country index start in January 1970, except for Finland, Ireland, Israel, New Zealand, and Portugal. The earliest monthly return series for emerging markets become available in January 1988.

\footnotetext{
${ }^{7}$ None of our results are affected qualitatively if consumption is measured in local currency units.

${ }^{8}$ Section 2.1 contains a full list of countries.
} 


\subsection{Equity Portfolios Construction}

This section describes the construction of international equity portfolios from the perspective of a US investor. The following section summarizes the main properties of these portfolios.

Jagannathan and Wang (2007) underscore that most investors revise their consumption and investment decisions simultaneously by the end of the calendar year. They argue that while agents may make both consumption and investment choices during other time periods, these two types of decisions are most likely to be related to each other at the end of each calendar year because of Christmas, the realized bonus payments and tax considerations. In general, while quarterly consumption growth is too volatile, cumulating consumption over several quarters should promise a more accurate approximation of true consumption spending. For US data, Jagannathan and Wang (2007) show that matching calendar year returns with growth rates in year-over-year fourth quarter aggregate consumption generates the most support for the consumption CAPM.

Conventional asset pricing models imply that there should be stable patterns between average asset returns and their sensitivities to sources of risk contemporaneously. Hence, evidence in favor of these models typically entails tests of a contemporaneous relationship between realized covariance between asset return and a risk factor with the realized average return of that asset (see e.g. Ang et al. (2006)). Black et al. (1972), Fama and MacBeth (1973), Fama and French (1992), Jagannathan and Wang (1996), Lettau and Ludvigson (2001), and Bansal et al. (2005), among others, employ risk measures that are measured over the same time period as returns. Furthermore, sorting on 
contemporaneous as opposed past characteristics is particularly appropriate in view of the poor ability of consumption growth to predict future stock returns (e.g. Yu (2012)). Against this backdrop, we build six equity portfolios by sorting all equity indices in the sample by the countries' year-over-year consumption growth rates based upon the fourth quarter. As we focus on a US investor who invests in foreign equity indices, both equity index returns and international consumption growth series are denominated in USD. Portfolios are rebalanced at the end of each December, such that portfolio 1 always contains the equity indices with the lowest fourth-quarter-over-fourth-quarter consumption growth rates, while portfolio 6 always contains the equity indices with the highest fourth-quarter-over-fourth-quarter consumption growth rates. We calculate the $\log$ equity excess return for portfolio $j$ by taking the average of the log equity index excess returns in each portfolio $j$ over the risk-free rate in each month over the same calendar year.

The total number of countries in our portfolios varies over time from 16 at the beginning of the sample to 28 at the end of sample. The maximum number of equity indices attained during the sample is 47 . As regards the choice of a total number of portfolios, we follow Lustig et al. (2011) and construct six portfolios for all countries and five portfolios for a smaller subset of developed countries. ${ }^{9}$ Our experiments with alternative number of portfolio bins lead generally to similar qualitative evidence.

\subsection{Returns to International Equity Portfolios}

Table I provides an overview of the properties of the international equity portfolios from the perspective of a US investor. The upper panel summarizes the descriptive statistics

\footnotetext{
${ }^{9}$ For example, Menkhoff et al. (2012) work with five, while Lustig and Verdelhan (2007) construct eight portfolios.
} 
for six portfolios from all 47 countries; the lower panel presents the descriptive statistics for five portfolios from a subsample of 25 developed countries. The portfolios are sorted annually on year-over-year consumption growth based upon the fourth quarter such that the first portfolio always contains markets with the lowest consumption growth rates, while the last portfolio always contains markets with the highest consumption growth rates. For each portfolio, the table also reports the average log year-over-year consumption growth based upon the fourth quarter and its standard deviation. Consumption is real, seasonally adjusted, in per capita terms, measured in USD.

In addition, we build and report results for a portfolio that is the average of all equity portfolios. We refer to this portfolio as the "dollar portfolio" $(R X)$ in analogy to Lustig et al. (2011). We also report results for the portfolio returns on our global consumption factor computed as the difference between the returns on portfolios with the highest and the lowest consumption growth rates $(H M L)$. The payoff on this factor is similar to the return on a zero-cost investment strategy which is long in high long-run consumption growth markets and short in low long-run consumption growth markets. All returns are excess returns in USD.

Average monthly excess returns tend to increase from low consumption growth markets to high consumption growth markets. The relation is almost monotonic, as shown in Figure 1. Average excess return on the first portfolio is 0.18 percent for all countries and 0.12 percent for developed countries. The last portfolio exhibits an average monthly excess return of 1.03 percent for all countries and 0.70 percent for developed countries. There are similar patterns in the portfolios' Sharpe ratios. The underlying consumption 
growth rates vary from -0.03 to 0.08 in the full sample, and from -0.01 to 0.06 for developed market countries.

The average unconditional excess returns from holding an equally weighted portfolio of international equity indices $(R X)$ is about 0.46 percent for all countries and 0.34 percent for developed countries. These figures suggest that a US investor demands a positive premium for holding international equity. The average excess return on our global consumption factor $(H M L)$ is roughly 0.85 percent in monthly terms for all countries and 0.58 percent for developed countries. It is important to note that the return on the $H M L$ factor is almost twice as high as the return on the $R X$ factor. This indicates a higher risk premium for the high-minus-low consumption-growth based trading strategy compared to a "market portfolio" based investment strategy.

Figure 2 shows cumulative log returns for the global consumption factor $(H M L)$ for all countries and for a subsample of developed countries. Shaded areas correspond to NBER recessions. Interestingly, up until the late 1990's we observe roughly similar returns on the $H M L$ factor from all and developed countries. Only after the millennium did the inclusion of emerging markets markedly improve the returns on a high-minus-low consumption growth investment strategy. It is also worth mentioning that recessions do not appear to affect the payoff on the $H M L$ factor. ${ }^{10}$ Yet, this observation hides the strong impact of economic recessions on the equity markets in general as visualized in Figures 3A and 3B. These figures plot cumulative log excess returns on the highest and lowest fourth-quarter-over-fourth-quarter consumption growth equity portfolios for the full sample and a subsample of developed countries, respectively. The last recession, which

\footnotetext{
${ }^{10}$ Menkhoff et al. (2012) document similar evidence for the $H M L$ factor in currencies.
} 
also saw a dramatic financial crisis, affected equity markets particularly severely. Most importantly, however, Figures $3 \mathrm{~A}$ and $3 \mathrm{~B}$ demonstrate that there are systematic differences in markets with different macroeconomic fundamentals: Investments based on low long-run consumption growth rate markets are associated with economically low gains or losses for long-term equity investors, while investments based on high long-run consumption growth rate markets promise strong profitability in the long term.

We obtain similar evidence when we repeat the exercise but use countries' fourthquarter-over-fourth-quarter consumption growth denominated in local currency as a sorting criterion to build equity bins. The descriptive statistics of these international equity portfolios are summarized in Table II.

So far, we have engineered a significant cross-sectional spread in equity excess returns by sorting countries' equity indices into portfolios based on the underlying aggregate fourthquarter-over-fourth-quarter annual consumption growth. In order to explain the variation in these equity excess returns, we study linear factor models with consumption-rated risk factors which are our common risk factors in equity returns.

\section{Global Consumption Risk and Equity Returns}

Lustig et al. (2011) employ a data-driven approach arising from the APT of Ross (1976) to identify two common risk factors in currency returns: the average currency excess return of a set of currencies against the USD, termed "the dollar factor" $(R X)$, and a socalled "carry trade risk factor" in currencies which is equivalent to a high-minus-low $\left(H M L_{F X}\right)$ strategy that buys currencies with high interest rates and sells currencies with low interest rates. In the present paper, we relate equity returns to two common risk factors in equity returns: "the dollar factor" $(R X)$ in equities, and the "global consumption 
factor" in equities which is equivalent to a high-minus-low $(H M L)$ strategy with a long position in markets with high year-over-year consumption growth rates based upon the fourth quarter and a short position in markets with low year-over-year consumption growth rates based upon the fourth quarter. We first document that the dollar factor has no pricing power while the global consumption factor explains a significant part of variation in equity returns. Cross-sectional spreads in international equity returns are matched by these two common risk factors in equities. We then argue that that our global consumption factor reflects unexpected changes in the cross-country consumption dispersion. Empirically, we find that high consumption growth economies have considerably higher consumption dispersion risk than low consumption growth economies, and this can explain their higher average returns.

\subsection{Common Factors in Equity Returns}

The APT of Ross (1976) states that risk exposures to a small number of factors should explain common variation in asset returns. A principal component analysis of our equity portfolio returns reveals that two factors can explain more than $80 \%$ of the variation in these test assets. Table III reports the principal components loadings of our equity portfolios presented in Table I, and shows the share of the total variance explained by each common factor. The first principal component explains about $75 \%$ of the comovement in international equity market returns, while the second principal component is responsible for roughly $7 \%$ of the comovement. Interestingly, all portfolios load almost equally on the first factor but reveal a monotonic pattern with respect to the second factor and do not exhibit any systematic relation as regards the remaining factors. The bottom panel of Table III confirms that we obtain similar evidence based on a 
subsample of developed markets. It is suggestive to assume that the monotonic pattern in average returns across portfolios documented in Table I is linked to the monotonic pattern in portfolio loadings with respective to the second principal component, and the latter should be informative about the cross-section of international equity excess returns. Against this backdrop, we follow Lustig et al. (2011) and construct two candidate common risk factors in equity returns: the average equity excess return, denoted $R X$, and the difference between the return on the last portfolio with high consumption growth rate equities and the first portfolio with low consumption growth rate equities, denoted $H M L$. The correlation of the first principal component with $R X$ is 0.99 ; the correlation of the second principal component with $H M L$ is -0.92 . We find figures of a similar order of magnitude for a subsample of developed countries: The correlation of the first principal component with $R X$ is 0.99 ; the correlation of the second principal component with $H M L$ is -0.99 .

Similar to the two common risk factors in currency markets documented in Lustig et al. (2011), the two common risk factors in equity markets are easily interpreted economically. $R X$ is the average excess return a US investor can realize from investing in a well-diversified portfolio of all available international equities. It is virtually the international equity "market" return. $H M L$ is the return from a trading strategy which is short in low consumption growth economies and long in high consumption growth economies.

\subsection{Beta Representation}

Our asset pricing tests rely on a two-stage regression methodology of Fama and MacBeth (1973) which emerges as one of the most popular approaches for estimating and testing 
linear asset pricing models. The first stage runs an unconditional time-series regression of $\log$ excess return $r x_{t+1}^{j}$ on portfolio $j$ on the risk factors for each equity portfolio $j$ separately $(j=1, \ldots, N)$ :

$$
r x_{t+1}^{j}=\beta_{0}^{j}+\beta_{R X}^{j} R X_{t+1}+\beta_{H M L}^{j} H M L_{t+1}+\varepsilon_{t+1}^{j},
$$

where $R X_{t+1}$ is the return on the dollar factor, $H M L_{t+1}$ is the return on the global consumption factor, $\beta_{0}^{j}$ is a constant, and $\varepsilon_{t+1}^{j}$ is an idiosyncratic error term.

In the second stage, the factor risk premiums $\lambda_{R X}$ and $\lambda_{H M L}$ are estimated from a single cross-sectional regression of average excess returns on the betas obtained in the first stage. In unconditional terms, the beta pricing model is defined as

$$
E\left(r x^{j}\right)=\lambda_{R X} \beta_{R X}^{j}+\lambda_{H M L} \beta_{H M L}^{j},
$$

where $E$ denotes the expectation operator, and $\lambda_{R X}$ and $\lambda_{H M L}$ are the risk premium estimates associated with the two common risk factors in equities. Relation (2) states that the expected excess return on a risky asset $j$ is linear in its betas.

The beta representation follows from the basic Euler equation for a US investor

$$
E_{t}\left(m_{t+1} r x_{t+1}^{j}\right)=0
$$

with a linear stochastic discount factor (SDF) given by

$$
m_{t+1}=1-b_{R X}\left(R X_{t+1}-\mu_{R X}\right)-b_{H M L}\left(H M L_{t+1}-\mu_{H M L}\right),
$$

where $b_{R X}$ and $b_{H M L}$ are the SDF parameters, and $\mu_{R X}$ and $\mu_{H M L}$ denote factor means. The relation between the factor risk prices in Equation (2) and the SDF parameters in Equation (4) follows $\lambda=\Sigma_{f f} b$ where $\Sigma_{f f}$ is the variance-covariance matrix of the pricing factors $R X$ and $H M L$, and $b=\left(b_{R X}, b_{H M L}\right)^{\prime}$. 
Several points are worth mentioning as regards the empirical implementation of and statistical inference in the cross-sectional asset pricing tests. First, Lewellen et al. (2010) emphasize the importance of imposing theoretical restrictions ex ante and caution against a false treatment of the slopes in the second stage of Fama and MacBeth (1973) regressions as free parameters. We address this concern by enforcing a zero-beta restriction, i.e. we do not include a constant in the second-stage equation as the $R X$ factor works virtually as a constant. ${ }^{11}$ Second, Kan and Robotti (2012) note that computing the average risk premiums and the $R^{2}$ from time-series estimates of lambdas and $R^{2}$ statistics is dangerous, as this procedure may neglect the economic and statistical significance. Against this backdrop, we follow a recommendation of Kan et al. (2013) and run a single cross-sectional regression of average excess returns on the full sample beta estimates. As a measure of "goodness-of-fit" we employ the adjusted $\bar{R}^{2}$ in a single cross-sectional regression for average returns. Third, as the betas in the second-stage regression are measured with error, the risk prices in Equation (2) are subject to the errors-in-variables bias. We follow Shanken (1992) to take into account the sampling errors in the betas obtained in the first stage. We also report the Fama and MacBeth (1973) standard errors as Jagannathan and Wang (1998) show that the uncorrected Fama and MacBeth standard errors do not necessarily overstate the precision of estimates in the presence of conditional heteroskedasticity. Fourth, Cochrane (2005) compares the Fama and MacBeth (1973) procedure with the generalized method of moments (GMM) applied to linear factor models. We present the results obtained with GMM as a robustness check. Finally, if the regression residuals in Equation (2) are correlated with each other, the

\footnotetext{
${ }^{11}$ Lustig et al. (2011) discuss this issue in further details. None of our conclusions are significantly affected by this restriction.
} 
standard textbook recommendation is to run a GLS cross-sectional regression instead of OLS (Cochrane (2005)). However, as the weighting matrix may be generally hard to estimate or invert, efficiency gains of GLS over OLS are associated with robustness losses. In one of our robustness checks, we show that both OLS and GLS estimation procedures generate similar results

\subsection{Benchmark Asset Pricing Tests}

This section presents our main finding that equity excess returns can be understood as compensation for their exposure to global consumption risk. This result is independent of the estimation procedure and is robust over time and across test assets.

Table IV reports our baseline asset pricing results for a linear factor model based on the dollar risk factor in equities $(R X)$ and the global consumption factor in equities $(H M L)$. The left half of the table employs six annually rebalanced equity portfolios from all countries detailed above as test assets. The right half of the table uses the five equity portfolios from a subset of developed countries.

Panel A of Table IV reports OLS estimates of betas obtained by running time-series regressions for each portfolio's equity excess returns on a constant and risk factors. In parentheses below coefficient estimates, we report Newey and West (1987) heteroskedasticity and autocorrelation (HAC) adjusted $t$-statistics with optimal lag length selection. The first column gives the constant terms, the second column gives the estimated betas for the dollar factor, and the third column reports the estimated betas for the global consumption factor. The beta estimates for the $R X$ factor are all about unity. Presumably, this factor cannot capture cross-sectional return differentials across portfolios, but it is important for explaining the average level of excess returns as 
indicated by the high statistical significance of the estimates. In contrast, we find a clear monotonic pattern in the $H M L$ betas: These betas increase from negative -0.49 for the first portfolio with the lowest consumption growth economies to positive 0.50 for the last portfolio with the highest consumption growth economies. The first two portfolios have negative betas, the middle two portfolios have close to zero betas, and the last two portfolios have positive betas. Our parsimonious model with two common risk factors explains between $75 \%$ and $90 \%$ of the time-series variation in equity portfolios returns. These results are robust and similar to those obtained for a subsample of developed countries as shown in the right half of the panel.

Panel B of Table IV reports estimates of factor risk prices obtained by Fama and MacBeth (1973) cross-sectional regressions. We follow Lustig et al. (2011) and do not include a constant in the second stage regressions. Below coefficient estimates we include two $t$-statistics: Shanken (1992) adjusted $t$-statistics are reported in parentheses and the Fama and MacBeth (1973) $t$-statistics are in square brackets. The last two columns give the cross-sectional adjusted $\bar{R}^{2}$ and the annualized root mean squared error $(R M S E)$ in percentage points.

We find a positive and statistically significant estimate for the market price of $H M L$ risk of about 90 basis points in monthly terms. This means that an asset with a beta of one earns a risk premium of about $10.8 \%$ per annum. The estimated market price corresponds closely to the average excess return on $H M L$ of 85 basis points. These results are indicative of investors who demand a positive premium for bearing global consumption risk in international equity markets. 
In stark contrast, the $R X$ risk factor obtains a premium which is further away from the actual factor mean. Its standard error is high and statistical significance very low. Thus, this factor cannot explain differences in average returns across portfolios. This result is not surprising, however, since our portfolios display virtually no dispersion in their exposure to the dollar risk factor. While the $R X$ factor is less informative about the crosssection of expected excess returns, it is important to capture the level of average returns correctly. As noted in Lustig et al. (2011), this factor acts as a constant in the crosssectional regressions. Replacing the dollar factor with a constant has almost no impact on the $H M L$ risk premium estimate and the general fit of the regression but this leads to an increase in the RMSE from 430 to 457 basis points.

In total, the evidence in Table IV supports that global consumption risk explains a large share of the cross-sectional variation in equity returns. The cross-sectional $\bar{R}^{2}$ exceeds $70 \%$, and our inference turns out similar for developed countries as reported on the righthand side of Panel B of the table.

In the following, we demonstrate that these results are independent of the estimation methodology and test assets used. Table V provides a summary of cross-sectional pricing results obtained using the GMM (Panel A), GLS (Panel B), and OLS (Panel C) estimation techniques for the two-factor linear model with the dollar risk factor $(R X)$ and the global consumption factor in equities $(H M L)$. Table $\mathrm{V}$ differs from Table IV in that it uses four alternative variants of MSCI equity indices to form equity portfolios based on fourth-quarter-over-fourth-quarter consumption growth: (I) the standard indices employed to construct our baseline portfolios presented in Table I; (II) indices of small caps; (III) indices with net dividends, i.e. net total return indices reinvest dividends after 
the deduction of withholding taxes; and (IV) indices with gross dividends, i.e. gross total return indices reinvest as much as possible of a company's dividend distribution.

Panel A of Table V presents the estimates of factor loadings in Equation (4) and factor prices in Equation (2) obtained with the two-stage GMM of Hansen and Singleton (1982). In the implementation of GMM, we follow Lustig and Verdelhan (2007) and use the pricing errors as a set of unconditional moments, i.e. we do not include instruments other than a constant vector of ones. The first-stage GMM estimation employs an identity weighting matrix aiming to weight all assets equally when computing the pricing errors. The second-stage GMM uses an optimal weighting matrix based on a HAC variancecovariance matrix of the moment conditions to attach more weight to more accurately priced assets. In parentheses below the estimates we report GMM HAC $t$-statistics. The $t$ statistics on $b_{H M L}$ consistently support the importance of the $H M L$ factor for the crosssection of average equity returns across different index return computation methods (I)(IV) for a full sample of all countries and for a subsample of developed countries. The SDF parameters or factor loadings are conventionally interpreted as regression coefficients in a multiple regression of the SDF on the factors.

A positive risk premium for the $H M L$ factor gives further support for the idea that investors require a reward for the global consumption risk exposure. Thus, economies with greater sensitivity to fluctuations in global consumption risk should generate on average higher returns. The risk price for the $H M L$ factor lies between $0.56 \%$ and $0.98 \%$ in monthly terms. The model generates a nice cross-sectional fit with $\bar{R}^{2}$ statistics of about $70 \%$ to $80 \%$ on average for all and developed countries, respectively. The model fit is slightly lower in the case of small caps as those are known to be particularly 
challenging to price. In general, our results support the view that investors with access to international equity markets demand a high return for assets with strong sensitivity to the global consumption factor.

We obtain similar results with cross-sectional GLS and OLS regressions in Panels B and $\mathrm{C}$ of Table V, respectively, because in the case of linear factor models, the GMM is equivalent to running a regression of average returns on the cross-moment of returns and factors without a constant in the regression. Based on this evidence, we report only the OLS two-pass cross-sectional regressions in the rest of the article as they are representative for alternative estimation methodologies.

\subsection{Robustness}

This section provides additional evidence supporting the association of equity returns with global consumption risk.

\subsubsection{Time Span Split}

First, in order to show that our results do not depend on the specific time period we investigate, we choose to split our sample in May 2002 as in this period all 47 MSCI equity indices become available.

The left half of Table VI presents the asset pricing results for the early sample running from January 1970 to May 2002. The right half of Table VI reports the findings for the late sample running from June 2002 to December 2012. The structure of the table is otherwise similar to Table IV.

The estimates in Table VI support the importance of global consumption risk for international equity markets. First, the $H M L$ loadings of portfolios are increasing from low consumption growth portfolios to high consumption growth portfolios over both 
subsamples. Second, the $H M L$ factor is measured with a high precision before and after May 2002 as indicated in Panel B of the table. Finally and most interestingly, the importance of the global consumption risk has increased over time: Our parsimonious linear two-factor model becomes more successful in capturing the time-variation of portfolio returns in the modern period. In addition, the risk premium estimate has increased from $0.75 \%$ to $1.28 \%$ recently.

\subsubsection{Alphabetic Country Split}

Second, to guard against the possibility of a mechanical relation between the returns and the factors, we randomly split our sample of 47 developed and emerging countries into one subsample with 23 countries and another subsample with 24 countries. To do so, we sort all countries alphabetically and consider Group I of countries with first letters A-I and Group II of countries with first letters J-U. For each group, we build five equity portfolios by sorting MSCI equity indices based on fourth-quarter-over-fourth-quarter consumption growth as described in Section 2.3.

Table VII reports the cross-sectional pricing results for both groups. We find that risk factors constructed on the basis of these test assets can still provide a reliable explanation of cross-sectional differences in average returns across portfolios. Similar to our benchmark finding, the $H M L$ betas tend to increase from low to high consumption growth markets in both groups. The two-factor model with $R X$ and $H M L$ risk factors has a lower $\bar{R}^{2}$ when faced with Group I due to the fact that these portfolio returns do not reveal a substantial dispersion: These average excess return on the-highest-over-the-lowest portfolios is about $0.33 \%$. By contrast, the average return on the $H M L$ factor is more than $1.22 \%$ for Group B and this factor explain more than $82 \%$ of the average return 
differentials. This evidence supports that the common risk factors considered in this paper are at work on equity markets.

\subsubsection{Country-Level Asset Pricing}

Third, we follow Lutig et al. (2011) and take our model to country-level data, i.e. we study the performance of the dollar factor and the global consumption factor for individual country-level MSCI index returns. This approach responds to a recent criticism raised by Ang et al. (2010) that portfolio construction might shrink the dispersion in betas and thus lead to biases in the statistical inference.

Empirically, we study a beta framework in which betas are time-varying functions of individual countries' consumption growth. In particular, this approach for estimating dynamic factor loadings assumes that $\beta_{R X, t}^{k}=d_{0}^{k}+d_{1}^{k} z_{t}^{k}$ and $\beta_{H M L, t}^{k}=h_{0}^{k}+h_{1}^{k} z_{t}^{k}$, where $z_{t}^{k}$ is country $k$ fourth-quarter-over-fourth-quarter consumption growth. The parameters $d_{0}^{k}, d_{1}^{k}, h_{0}^{k}$, and $h_{1}^{k}$ are easily estimated from the following time-series regression for each country $k$ :

$$
r x_{t+1}^{k}=c^{k}+d_{0}^{k} R X_{t+1}+d_{1}^{k} z_{t}^{k} R X_{t+1}+h_{0}^{k} H M L_{t+1}+h_{1}^{k} z_{t}^{k} H M L_{t+1}+\varepsilon_{t+1}^{k} .
$$

The time-varying factor risk prices can then be estimated from a series of cross-sectional regressions of returns on the fitted conditional betas:

$$
r x_{t+1}^{k}=\lambda_{R X, t+1} \beta_{R X, t+1}^{k}+\lambda_{H M L, t+1} \beta_{H M L, t+1}^{k}+\xi_{t+1}^{k} .
$$

Finally, the model's cross-sectional fit can be evaluated by comparing the true unconditional excess returns with their predicted values:

$$
E\left(r x_{t+1}^{k}\right)=E\left(\lambda_{R X, t+1} \beta_{R X, t+1}^{k}+\lambda_{H M L, t+1} \beta_{H M L, t+1}^{k}\right) .
$$


The results of this estimation are provided in Panel A Table VIII. To compute the conditional betas we rely on four different proxies for $z_{t}^{k}$ : Column (I) of the table employs individual countries' real per capita year-over-year capita consumption growth based upon the fourth quarter and measured in USD; Column (II) uses the gross domestic product (GDP)-weighted annual consumption growth rates based upon the fourth quarter and measured in USD; Column (III) employs individual countries' fourth-quarter-overfourth-quarter consumption growth measured in local currency units; and finally, Column (IV) uses GDP-weighted annual consumption growth rates based upon the fourth quarter and measured in local currency units.

To guarantee that our results are not affected by excluding a constant from the secondstage Fama and MacBeth (1973) regressions, we re-estimate an unrestricted version of the two-factor model which allows for common under- or over-pricing, i.e. we include a constant term in the cross-sectional regressions in Panel B of Table VIII.

The country-level results are generally consistent with the portfolio-level evidence: While the global consumption risk obtains a significant premium, the risk price of the dollar factor in equities is mostly insignificant and often negative. When faced with individual country index returns, the model generates a slightly lower fit as the number of test assets goes up from 6 portfolios for all countries to 47 individual country indices, and from 5 portfolios for developed countries to 25 individual country indices.

\subsubsection{Beta-Sorted Portfolios}

We next explore the explanatory power of global consumption risk from a different perspective. If fluctuations in the global consumption factor, as measured by $H M L$, are a source of priced risk in equity markets, then it is reasonable to assume that sorting equity 
indices according to their exposure to $H M L$ generates a significant spread in mean returns. Equities which hedge against global consumption risk should trade at a premium, while equities which fail to payoff when global consumption risk is high should yield on average higher expected excess returns.

To sort equity indices into portfolios, we follow Lustig et al. (2011) and use rolling window estimates of $H M L$ betas obtained in a 36-month moving window time-series regression of individual equity index log excess return on a constant and $H M L$. The first portfolio contains equities with the lowest $H M L$ betas; the last portfolio contains equities with the highest $H M L$ betas. The summary statistics of these portfolios are reported in Table IX.

The upper panel shows six portfolios from all countries; the lower panel shows five portfolios from developed countries. For each portfolio, the table reports mean returns in $\%$ per month, standard deviations and Sharpe ratios. In addition, it shows the average preformation $H M L$ betas and the estimates of the post-formation $H M L$ betas obtained by regressing realized log excess portfolio returns on a constant, $R X$ and $H M L$.

The table shows that average returns as well as their $H M L$ betas increase monotonically from the first portfolio to the last portfolio. Thus, sorts based on aggregate fourth-quarterover-fourth-quarter consumption growth and sorts based on betas are clearly related. This supports the view that year-over-year consumption growth based on the fourth quarter conveys important information about the riskiness of assets. Our results remain valid in a subsample of developed countries as demonstrated in the lower panel of Table IX and hold true for alternative rolling window lengths, different MSCI index specifications, and for both returns in USD and national currency units. 


\subsubsection{Additional Results}

We examine our main result in the following specifications without qualitative changes in our findings: We considered a lower and a higher number of portfolios, we studied quarterly and annual return frequencies, returns in nominal and real terms, returns denominated in USD and in local currency units. Instead of assuming fix betas over the full sample we allowed the betas to vary over time. To guard against the possibility that the first-stage Fama and MacBeth (1973) regression generates unreliable beta estimates due to a non-zero factor correlation, we followed the recommendation of Jagannathan and Wang (1998) and employed so-called univariate or simple regression betas estimated for each factor separately. We find that our results are robust to each of these changes and thus corroborate our core finding that global consumption risk is a key driver of risk premiums in equity markets.

\section{Rationalizing the Explanatory Power of $H M L$}

To the extent that there is sufficient heterogeneity in countries' consumption patterns, for example because of the presence of persistent idiosyncratic shocks, the economic theory predicts that besides the world aggregate consumption growth, the cross-country variance of consumption growth becomes an important factor to explain price changes (e.g. Ramchand (1999)). Surprisingly, the impact of cross-country consumption dispersion on asset returns has received little attention in empirical tests of consumption-based asset pricing models-most papers focus on the imperfect consumption risk sharing across individuals for domestic stock returns (e.g. Brav et al. (2002), Cogley (2002), and Jacobs and Wang (2004)), or they focus on other markets and do not examine equities.

\subsection{Theoretical Motivation}


To examine the impact of imperfect international consumption risk sharing on asset prices, Sarkissian (2003) extends the framework of the general equilibrium incomplete markets model of Constantinides and Duffie (1996) to a multi-country world. Abstracting from within-country consumption heterogeneity across individuals, Equation (3) can be rewritten as

$$
E_{t}\left[\left(\frac{C_{t+1}}{C_{t}}\right)^{-\gamma} \exp \left(\kappa \frac{\gamma(\gamma+1)}{2} W C D_{t+1}\right) r x_{t+1}^{j}\right]=0
$$

where $\frac{C_{t+1}}{C_{t}}$ is the world consumption growth, $\gamma$ is the relative risk aversion, $W C D_{t+1}$ is the world consumption dispersion measured as the cross-country variance of consumption growth rates, $\kappa$ is a scale factor representing the degree of mismeasured dispersion, and $r x_{t+1}^{j}$ refers here to discrete (rather than log) excess returns.

We then exploit the basic insight of the log utility CAPM of Rubinstein (1976) that consumption can be easily substituted out from a standard intertemporal asset pricing model (Cochrane (2005)). To the extent that the market (or total wealth) portfolio represents a claim to the future consumption stream, its price $P_{t}$ can be represented as

$$
P_{t}=E_{t} \sum_{j=1}^{\infty} \beta^{j} \frac{u^{\prime}\left(C_{t+j}\right)}{u^{\prime}\left(C_{t}\right)} C_{t+j}=\frac{\beta}{1-\beta} C_{t}
$$

and the "market return" $R X_{t}$ is then proportional to consumption growth:

$$
R X_{t}=\frac{P_{t+1}+C_{t+1}}{C_{t}}=\frac{(\beta /(1-\beta)+1)}{\beta /(1-\beta)} \frac{C_{t+1}}{C_{t}}=\frac{1}{\beta} \frac{C_{t+1}}{C_{t}},
$$

where $\beta, \beta \in(0,1)$ is a constant known as a subjective discount factor. 
Thus, in the case of $\log$ utility and under the assumption that the joint conditional distribution of consumption growth, consumption dispersion, and asset returns is lognormal, Equation (8) implies the following approximate beta pricing relation ${ }^{12}$ :

$$
E\left(r x^{j}\right) \approx \lambda_{R X} \beta_{R X}^{j}+\lambda_{W C D} \beta_{W C D}^{j} .
$$

In this specification, the return on portfolio $j$ is determined by its covariance with two state variables: the aggregate market return proxied by the average equity excess return or our dollar factor in equities $(R X)$, and world consumption dispersion $(W C D)$ measured as the cross-sectional variance in countries' consumption growth rates. It is interesting to note that the only difference between the representation in Equation (11) and our baseline specification in Equation (2) is that $H M L$ is now replaced with $W C D$. If our global consumption factor indeed reflects changes in global consumption dispersion, we should find a significant premium for $W C D$. Specifically, finance theory predicts a negative price of dispersion risk, as assets which payoff well when international consumption risk sharing is low and countries' consumption growth rates differ widely, might be valuable for investors willing to hedge against macroeconomic fluctuations.

\subsection{Measuring World Consumption Dispersion}

We use a straightforward measure of world consumption dispersion. More specifically, we calculate the cross-sectional variance of log consumption growth rates of all countries in our sample at the end of each December. Consumption series are real, seasonally adjusted, in per capita terms, and denominated in local currency units in line with the arguments outlined in Sarkissian (2003). To assure consistency with our previous

\footnotetext{
${ }^{12}$ Equation (9) obtains analogously to Equation (7) in Sarkissian (2003), i.e. if one neglects the differences in distributional properties of $W C D$ and $\exp (W C D)$.
} 
analysis, we work with fourth-quarter-over-fourth-quarter consumption growth rates. Our world consumption dispersion proxy is thus given by

$$
W C D_{t}=\operatorname{var}_{K}\left[\ln \left(\frac{C_{t}^{k}}{C_{t-1}^{k}}\right)\right],
$$

where $C_{t}^{k}$ is the aggregate consumption in country $k$ in the fourth quarter of year $t$ and $\operatorname{var}_{K}$ denotes the cross-sectional variance (dispersion) of $K$ countries' consumption growth rates. Figure 4 shows a time-series plot of $W C D$. Shaded areas in the figure correspond to NBER recessions. As expected, the dispersion is strongly countercyclical-it is high in recessions and low in booms, and this feature of the data might be helpful for equity pricing.

For the empirical analysis, we focus on dispersion innovations as a non-traded risk factor (see e.g. Menkhoff et al. (2012) and Assness et al. (2013)). We tried several alternative ways to measure innovations. The easiest way to do this is to take first differences of the dispersion series in Equation (12) (see e.g. Ang et al. (2006)). First differences are, however, significantly autocorrelated of the order of -0.5 . We therefore define dispersion innovations as the residuals from an $\mathrm{AR}(2)$ model for $W C D$, as these residuals are uncorrelated with their own lags. ${ }^{13}$ A plot of these AR(2)-based dispersion innovations is shown as a dotted line in Figure 4.

\subsection{Asset Pricing Tests with Consumption Dispersion Risk}

Table $\mathrm{X}$ presents results of our asset pricing tests using the six (five) equity portfolios from all (developed) countries sorted annually on fourth-quarter-over-fourth-quarter consumption growth. As factors we use the dollar risk factor $(R X)$ and innovations to the

\footnotetext{
13 Autoregressive models $\mathrm{AR}(1)$ and $\mathrm{AR}(3)$ and unconditional cross-sectional dispersion measures yield similar results.
} 
world consumption dispersion (WCD) based on the residuals of an $\operatorname{AR}(2)$ process for the cross-sectional variance in countries' log fourth-quarter-over-fourth-quarter consumption growth rates.

Panel A of Table $\mathrm{X}$ shows time-series beta estimates for the equity portfolios based on the full sample and the developed country sample. Similar to our previous findings, the $R X$ betas are around one for all portfolios. By contrast, there is a substantial variation in the $W C D$ betas. In particular, the estimates of $W C D$ betas are large and positive for equities with low consumption growth rates, whereas countries with high consumption growth rates tend to co-move negatively with world consumption dispersion innovations. There is nearly a monotonic pattern in the $W C D$ betas from the first to the last portfolio. Thus, equity investments with high global consumption risk (high $H M L$ betas) perform particularly poorly in periods of high consumption dispersion, while equities with low global consumption risk (low $H M L$ betas) provide a hedge against periods of macroeconomic turmoil. This observation is true for all portfolios of developed countries and all portfolios from the full sample except for P5.

These spreads in betas translate in negative estimates for the $W C D$ risk price in Panel B of Table X. The price of dispersion risk is negative, consistent with the view that assets which perform poorly in uncertain aggregate times require higher expected returns. The negative factor price guarantees lower risk premiums for portfolios whose returns comove positively with dispersion innovations, i.e. hedge against dispersion risk. The $W C D$ risk premium is measured with a larger standard error for a subsample of developed countries compared to the full sample estimates. Judged by the overall model fit and the average pricing errors, the dispersion risk is able to reproduce the spread in mean returns 
to a certain degree. We obtain similar results when we use alternative proxies for the dispersion risk. We experimented with innovations from higher and lower autoregressive processes for $W C D$, employed both the cross-sectional variance and standard deviation as a measure of cross-country dispersion, and worked with dispersion in levels instead of innovations.

Yet, it is interesting to note that a model with consumption dispersion risk in Table $\mathrm{X}$ captures less variation in average returns than the original benchmark specification with global consumption risk presented in Table IV. This result is intuitive as our dispersion proxy does not use information on equity markets as opposed to the return on the $H M L$ factor mimicking portfolio. In a horse-race between $H M L$ and $W C D$, the latter should therefore not be able to replace the former. Indeed, our estimates in Table XI strongly support this intuition. The global consumption risk factor dominates the dispersion risk factor when both are included jointly in the model.

Finally, we follow Ang et al. (2006) and Menkhoff et al. (2012) and build a factor mimicking portfolio for world consumption dispersion $(F W C D)$. To obtain the factor mimicking portfolio we regress dispersion innovations on equity portfolio excess returns

$$
W C D_{t+1}=a+b^{\prime} R X_{t+1}^{J}+u_{t+1}
$$

where $R X_{t+1}^{J}$ is the vector of excess return of the six equity portfolios. The factor mimicking portfolio excess return is then given by $b^{\prime} R X_{t+1}^{J}$. We find a correlation of about $-50 \%$ between $H M L$ and $F W C D$. The tests in Table XII give further support for our finding that high consumption growth economies have considerably higher consumption dispersion risk than low consumption growth economies, and this can explain between $20 \%$ and $40 \%$ of their cross-sectional return differentials. 
Our results indicate that heterogeneity in the exposure to unexpected changes in the cross-country consumption dispersion can partly rationalize the explanatory power of the global consumption risk factor. First, we find that equity return is higher the more negatively correlated it is with innovations in consumption dispersion. Second, we show that the latter becomes insignificant in the presence of the global consumption risk factor.

\section{Conclusions}

The key insight of the international consumption CAPM is that the systematic exposure to a single world consumption risk factor should justify differences in returns in international equity markets. However, empirical measures of world consumption growth risk have failed to rationalize the cross-section of country equity returns. This paper shows that a new risk factor-termed "the global consumption factor"-can explain the trade-off between risk and return reflected in equity premiums around the world.

We identify the global consumption factor in the data by constructing equity portfolios sorted by countries' fourth-quarter-over-fourth-quarter consumption growth rates based on the evidence in Jagannathan and Wang (2007) that matching calendar year returns with growth rates in year-over-year fourth quarter aggregate consumption avoids seasonal patterns in the data and generates most support for the consumption-based model. We find that the payoff on the global consumption factor, i.e. the spread in returns between baskets of high and low consumption growth markets, reflects changes in the crosscountry consumption dispersion and commands a significant premium to compensate investors for taking on common macroeconomic risks.

We show that high average returns on equity markets with high consumption growth rates can be explained as compensation for the macroeconomic risk undertaken. 
Economies with high consumption growth rates deliver low returns in states of high consumption dispersion. These markets must therefore have high expected returns to reward investors for bearing systematic risk. On the contrary, economies with low consumption growth rates payoff well when consumption dispersion surges, and this can explain why these markets have lower returns on average. Cross-country consumption dispersion is strongly countercyclical, and this feature of the data turns out helpful for equity pricing.

Our research has direct implications for practitioners: International portfolio investment decisions are best performed based on expected developments in economic fundamentals across countries. Recognising common macroeconomic risks can prevent in particular investors participating in global equity markets from overweighting high consumption growth economies as opposed to low consumption growth economies when constructing their optimally-hedging portfolios. Moreover, this article provides new evidence which supports the idea that common macroeconomic fundamentals are the key to understand differences in expected returns across assets and reinforces a risk-based view of equity premium formation. 


\section{References}

Ang, A., J. Liu, and K. Schwartz, 2010, Using Stocks or Portfolios in Tests of Factor Models, Working Paper.

Ang, A., J. Chen, and Y. Xing, 2006, Downside Risk, Review of Financial Studies 19, 1191-1239.

Ang, A., R. J. Hodrick, Y. Xing, and X. Zhang, 2006, The Cross-Section of Volatility and Expected Returns, Journal of Finance 61, 259-299.

Asness, C. S., T. J. Moskowitz, and L. H. Pedersen, 2013, Value and Momentum Everywhere, Journal of Finance 68, 929-985.

Bansal, R., R. Dittmar, and C. Lundblad, 2005, Consumption, Dividends, and the CrossSection of Equity Returns, Journal of Finance 60, 1639-1672.

Bansal, R., and A. Yaron, 2004, Risks for the Long Run: A Potential Resolution of Asset Pricing Puzzles, Journal of Finance 59, 1481-1509.

Black, F., M. Jensen, and M. Scholes, 1972, The Capital Asset Pricing Model: Some Empirical Tests. In: M.C. Jensen, M. C. (Ed.), Studies in the Theory of Capital Markets. Praeger, New York, 79-121.

Brav, A., G. Constantinides, and C. Geczy, 2002, Asset Pricing with Heterogeneous Consumers and Limited Participation: Empirical Evidence, Journal of Political Economy 110, 793-824.

Breeden, D., 1979, An Intertemporal Asset Pricing Model with Stochastic Consumption and Investment Opportunities, Journal of Financial Economics 7, 265-296.

Breeden, D., M. Gibbons, and R. Litzenberger, 1989, Empirical Tests of the Consumption-Oriented CAPM, Journal of Finance 44, 231-262. 
Campbell, J. Y., 1996, Understanding Risk and Return, Journal of Political Economy $104,298-345$.

Cochrane, J. H., 1996, A Cross-Sectional Test of an Investment-Based Asset Pricing Model, Journal of Political Economy 104, 572-621.

Cochrane, J. H., 2005, Asset Pricing. Princeton University Press, Princeton and Oxford.

Cogley, T., 2002, Idiosyncratic Risk and the Equity Premium: Evidence from the Consumer Expenditure Survey, Journal of Monetary Economics 49, 309-334.

Constantinides, G., and D. Duffie, 1996, Asset Pricing with Heterogeneous Consumers, Journal of Political Economy 104, 219-240.

Cumby, R. E., 1990, Consumption Risk and International Equity Returns: Some Empirical Evidence, Journal of International Money and Finance 9, 182-192.

Darrat, A. F., B. Li, and J. C. Park, 2011, Consumption-Based CAPM Models: International Evidence, Journal of Banking and Finance 35, 2148-2157.

Della Corte, P., S. J. Riddiough, and L. Sarno, 2014, Currency Premia and Global Imbalances. Working Paper.

Fama, E. F., 1976, Foundations of Finance: Portfolio Decisions and Securities Prices. New York: Basic Books.

Fama, E. F., and K. R. French, 1992, The Cross-Section of Expected Stock Returns, Journal of Finance 47, 427-465.

Fama, E. F., and J. MacBeth, 1973, Risk, Return, and Equilibrium: Empirical Tests. Journal of Political Economy 81, 607-636.

Gomes, F., and A. Michaelides, 2008, Asset Pricing with Limited Risk Sharing and Heterogeneous Agents, Review of Financial Studies 21, 415-448. 
Gomes, J.-P., R. Priestley, and F. Zapatero, 2009, Implications of Keeping-Up-with-theJoneses Behavior for the Equilibrium Cross Section of Stock Returns: International Evidence, Journal of Finance 64, 2703-2737.

Hansen, L., and K. Singleton, 1982, Generalized Instrumental Variables Estimation of Nonlinear Rational Expectations Models, Econometrica 55, 1269-1286.

Heaton, J., and D. Lucas, 1996, Evaluating the Effects of Incomplete Markets on Risk Sharing and Asset Pricing, Journal of Political Economy 104, 443-487.

Hoffmann M., and R. Suter, 2013, Systematic Consumption Risk in Currency Returns. Working Paper, University of Zurich.

Jacobs, K., and K. Q. Wang, 2004, Idiosyncratic Consumption Risk and the Cross Section of Asset Returns, Journal of Finance 59, 2211-2252.

Jagannathan, R., and Z. Wang, 1996, The Conditional CAPM and the Cross-Section of Expected Returns, Journal of Finance 51, 3-53.

Jagannathan, R., and Z. Wang, 1998, An Asymptotic Theory for Estimating Beta-Pricing Models Using Cross-Sectional Regression, Journal of Finance 53, 1285-1309.

Jagannathan, R., and Y. Wang, 2007, Lazy Investors, Discretionary Consumption, and the Cross-Section of Stock Returns, Journal of Finance 62, 1623-1661.

Kan, R., and C. Robotti, 2012, Evaluation of Asset Pricing Models Using Two-Pass Cross-Sectional Regressions. In: Duan, J.-C., Härdle, W. K., and J. E. Gentle (Eds.), Handbook of Computational Finance. Springer-Verlag, Berlin Heidelberg, 223-251.

Kan, R., C. Robotti, and J. Shanken, 2013, Pricing Model Performance and the Two-Pass Cross-Sectional Regression Methodology, Journal of Finance 68, 2617-2649. 
Karolyi, G. A., and R. M. Stulz, 2003, Are Financial Assets Priced Locally or Globally? In: Constantinides, G. M., M. Harris, and R. M. Stulz (Eds.), The Handbook of the Economics of Finance. Amsterdam, North-Holland, 975-1020.

Lettau, M., and S. Ludvigson, 2001, Resurrecting the (C)CAPM: A Cross-Sectional Test When Risk Premia Are Time-Varying, Journal of Political Economy 109, 1238-1287.

Lewellen, J., Nagel, S., and J. Shanken, 2010, A Skeptical Appraisal of Asset Pricing Tests, Journal of Financial Economics 96, 175-194.

Li, Y., 2010, Testing World Consumption Asset Pricing Models, European Journal of Economics, Finance and Administrative Sciences 22, 7-20.

Li, Y., and M. Zhong, 2005, Consumption Habit and International Stock Returns, Journal of Banking and Finance 29, 579-601.

Li, Y., and M. Zhong, 2009, International Asset Returns and Exchange Rates, European Journal of Finance 15, 263-285.

Lucas, R. E. Jr., 1978, Asset Prices in an Exchange Economy, Econometrica 46, 14291445.

Lustig, H. N., N. L. Roussanov, and A. Verdelhan, 2011, Common Risk Factors in Currency Markets, Review of Financial Studies 24, 3731-3777.

Lustig, H. N., and A. Verdelhan, 2007, The Cross Section of Foreign Currency Risk Premia and Consumption Growth Risk, American Economic Review 97, 89-117.

Mankiw, G. and M. Shapiro, 1986, Risk and Return: Consumption versus Market Beta, Review of Economics and Statistics 68, 452-459.

Menkhoff, L., L. Sarno, M. Schmeling, and A. Schrimpf, 2012, Carry Trades and Global Foreign Exchange Volatility, Journal of Finance 67, 681-718. 
Menkhoff, L., L. Sarno, M. Schmeling, and A. Schrimpf, 2013, Currency Risk Premia and Macro Fundamentals, Working Paper.

Newey, W. K., and K. D. West, 1987, A Simple, Positive Semi-Definite, Heteroskedasticity and Autocorrelation Consistent Covariance Matrix, Econometrica $55,703-708$.

Parker, J. A., and C. Julliard, 2005, Consumption Risk and the Cross Section of Expected Returns, Journal of Political Economy 113, 185-222.

Ramchand, L., 1999, Asset Pricing in International Markets in the Context of Agent Heterogeneity and Market Incompleteness, Journal of International Money and Finance 18, 871-890.

Rangvid, J., M. Schmeling, and A. Schrimpf, 2012, Long-Run Consumption Risk and International Stock Returns: A Century of Evidence, Working Paper.

Ross, S. A., 1976, The Arbitrage Theory of Capital Asset Pricing, Journal of Economic Theory 13, 341-360.

Rubinstein, M., 1976, The Valuation of Uncertain Income Streams and the Price of Options, Bell Journal of Economics 7, 407-425.

Sarkissian, S., 2003, Incomplete Consumption Risk Sharing and Currency Risk Premiums, Review of Financial Studies 16, 983-1005.

Shanken, J., 1992, On the Estimation of Beta-Pricing Models, Review of Financial Studies 5, 1-34.

Stulz, R. M., 1981, A Model of International Asset Pricing, Journal of Financial Economics 9, 383-406. 
Telmer, C. I., 1993, Asset Pricing Puzzles and Incomplete Markets, Journal of Finance 48, 1803-1832.

Wheatley, S., 1988, Some Tests of International Equity Integration, Journal of Financial Economics 21, 177-212.

Yu, J., 2012, Using Long-Run Consumption-Return Correlations to Test Asset Pricing Models, Review of Economic Dynamics 15, 317-335. 
Table I. Portfolios Sorted on Consumption Growth

The table reports mean returns, standard deviations, and Sharpe ratios (SR) for equity portfolios sorted annually on year-over-year consumption growth based upon the fourthquarter. The first portfolio contains equity indices with the lowest consumption growth rates. The last portfolio contains equity indices with the highest consumption growth rates. All returns are excess returns in USD. The upper panel shows six portfolios from all countries; the lower panel shows five portfolios from developed countries. $R X$ denotes the average excess return and $H M L$ denotes a strategy that is long in the last portfolio and short in the first portfolio. For each portfolio, the table also reports the average log yearover-year consumption growth based upon the fourth-quarter and its standard deviation. Consumption is real, in per capita terms, measured in USD. Returns are monthly and the sample period is January 1970 - December 2012.

\begin{tabular}{|c|c|c|c|c|c|c|c|c|}
\hline \multicolumn{9}{|c|}{ All Countries } \\
\hline & P1 & $\mathrm{P} 2$ & $\mathrm{P} 3$ & $\mathrm{P} 4$ & P5 & P6 & $R X$ & $H M L$ \\
\hline \multicolumn{9}{|c|}{ Excess Returns (in \%) } \\
\hline Mean & 0.18 & 0.16 & 0.28 & 0.47 & 0.68 & 1.03 & 0.46 & 0.85 \\
\hline Std. & 6.54 & 5.46 & 5.36 & 5.36 & 5.42 & 6.21 & 4.98 & 5.25 \\
\hline SR & 0.03 & 0.03 & 0.05 & 0.09 & 0.12 & 0.17 & 0.09 & 0.16 \\
\hline \multicolumn{9}{|c|}{ Consumption Growth } \\
\hline Mean & -0.03 & 0.01 & 0.02 & 0.03 & 0.04 & 0.08 & & \\
\hline Std. & 0.05 & 0.02 & 0.01 & 0.01 & 0.01 & 0.03 & & \\
\hline \multicolumn{9}{|c|}{ Developed Countries } \\
\hline & P1 & $\mathrm{P} 2$ & P3 & $\mathrm{P} 4$ & P5 & $R X$ & $H M L$ & \\
\hline \multicolumn{9}{|c|}{ Excess Returns (in \%) } \\
\hline Mean & 0.12 & 0.18 & 0.27 & 0.41 & 0.70 & 0.34 & 0.58 & \\
\hline Std. & 5.74 & 5.01 & 5.10 & 4.97 & 5.71 & 4.76 & 4.36 & \\
\hline SR & 0.02 & 0.04 & 0.05 & 0.08 & 0.12 & 0.07 & 0.13 & \\
\hline \multicolumn{9}{|c|}{ Consumption Growth } \\
\hline Mean & -0.01 & 0.01 & 0.02 & 0.03 & 0.06 & & & \\
\hline Std. & 0.02 & 0.01 & 0.01 & 0.01 & 0.02 & & & \\
\hline
\end{tabular}


Table II. Portfolios Sorted on Consumption Growth in Local Currency

The table reports mean returns, standard deviations, and Sharpe ratios (SR) for equity portfolios sorted annually on year-over-year consumption growth based upon the fourthquarter. The first portfolio contains equity indices with the lowest consumption growth rates. The last portfolio contains equity indices with the highest consumption growth rates. All returns are excess returns in USD. The upper panel shows six portfolios from all countries; the lower panel shows five portfolios from developed countries. $R X$ denotes the average excess return and $H M L$ denotes a strategy that is long in the last portfolio and short in the first portfolio. For each portfolio, the table also reports the average log yearover-year consumption growth based upon the fourth-quarter and its standard deviation. Consumption is real, in per capita terms, measured in national currency. Returns are monthly and the sample period is January 1970 - December 2012.

\begin{tabular}{|c|c|c|c|c|c|c|c|c|}
\hline \multicolumn{9}{|c|}{ All Countries } \\
\hline & P1 & $\mathrm{P} 2$ & P3 & P4 & P5 & P6 & $R X$ & $H M L$ \\
\hline \multicolumn{9}{|c|}{ Excess Returns (in \%) } \\
\hline Mean & 0.16 & 0.28 & 0.35 & 0.42 & 0.54 & 1.25 & 0.50 & 1.08 \\
\hline Std. & 6.45 & 5.44 & 5.31 & 5.47 & 5.33 & 6.73 & 5.04 & 5.40 \\
\hline SR & 0.03 & 0.05 & 0.07 & 0.08 & 0.10 & 0.19 & 0.10 & 0.20 \\
\hline \multicolumn{9}{|c|}{ Consumption Growth } \\
\hline Mean & -0.02 & 0.01 & 0.02 & 0.03 & 0.04 & 0.07 & & \\
\hline Std. & 0.03 & 0.01 & 0.01 & 0.01 & 0.01 & 0.02 & & \\
\hline \multicolumn{9}{|c|}{ Developed Countries } \\
\hline & P1 & $\mathrm{P} 2$ & P3 & $\mathrm{P} 4$ & P5 & $R X$ & $H M L$ & \\
\hline \multicolumn{9}{|c|}{ Excess Returns (in \%) } \\
\hline Mean & 0.16 & 0.09 & 0.27 & 0.53 & 0.71 & 0.35 & 0.54 & \\
\hline Std. & 5.45 & 5.29 & 5.04 & 5.12 & 5.84 & 4.78 & 4.13 & \\
\hline SR & 0.03 & 0.02 & 0.05 & 0.10 & 0.12 & 0.07 & 0.13 & \\
\hline \multicolumn{9}{|c|}{ Consumption Growth } \\
\hline Mean & -0.01 & 0.01 & 0.02 & 0.03 & 0.05 & & & \\
\hline Std. & 0.02 & 0.01 & 0.01 & 0.01 & 0.02 & & & \\
\hline
\end{tabular}


Table III. Principal Components

The table reports the principal component coefficients of the equity portfolios presented in Table I. In each panel, the last row reports (in \%) the share of the total variance explained by each common factor. Returns are monthly and the sample period is January 1970 - December 2012.

\begin{tabular}{|c|c|c|c|c|c|c|}
\hline \multicolumn{7}{|c|}{ All Countries } \\
\hline & P1 & $\mathrm{P} 2$ & P3 & P4 & P5 & P6 \\
\hline 1 & 0.46 & 0.84 & 0.22 & 0.13 & -0.13 & -0.03 \\
\hline 2 & 0.40 & 0.04 & -0.21 & -0.62 & 0.64 & 0.07 \\
\hline 3 & 0.38 & -0.15 & -0.45 & 0.70 & 0.33 & -0.20 \\
\hline 4 & 0.38 & -0.16 & -0.33 & -0.04 & -0.45 & 0.71 \\
\hline 5 & 0.39 & -0.24 & -0.14 & -0.30 & -0.49 & -0.66 \\
\hline 6 & 0.43 & -0.44 & 0.76 & 0.13 & 0.12 & 0.10 \\
\hline$\%$ Var. & 75.60 & 7.19 & 6.42 & 3.79 & 3.69 & 3.32 \\
\hline \multicolumn{7}{|c|}{ Developed Countries } \\
\hline & P1 & P2 & P3 & P4 & P5 & \\
\hline 1 & 0.48 & 0.78 & 0.39 & 0.07 & -0.08 & \\
\hline 2 & 0.43 & -0.02 & -0.24 & -0.49 & 0.72 & \\
\hline 3 & 0.43 & -0.06 & -0.50 & -0.35 & -0.67 & \\
\hline 4 & 0.42 & -0.11 & -0.40 & 0.80 & 0.16 & \\
\hline 5 & 0.48 & -0.61 & 0.61 & -0.00 & -0.10 & \\
\hline$\%$ Var. & 80.23 & 6.75 & 5.75 & 3.97 & 3.30 & \\
\hline
\end{tabular}




\section{Table IV. Asset Pricing}

The table reports cross-sectional pricing results for the linear factor model based on the dollar risk factor $(R X)$ and the consumption factor in equities $(H M L)$. The test assets are six (five) equity portfolios from all (developed) countries sorted annually on year-overyear consumption growth based upon the fourth-quarter presented in Table I. Panel A shows OLS estimates of betas with Newey and West (1987) $t$-statistics with optimal lag length in parentheses and adjusted $\bar{R}^{2}$ statistics in \%. Panel B shows coefficient estimates of factor risk prices obtained by Fama and MacBeth (1973) cross-sectional regressions. We do not include a constant in the second-stage regressions. Shanken (1992) corrected $t$-statistics are reported in parentheses and the Fama and MacBeth (1973) $t$-statistics appear in square brackets. The cross-sectional adjusted $\bar{R}^{2}$ statistics and the annualized root mean squared error (RMSE) are in \%. Returns are monthly and the sample period is January 1970 - December 2012.

\begin{tabular}{|c|c|c|c|c|c|c|c|c|}
\hline \multicolumn{9}{|c|}{ Panel A: Factor Betas } \\
\hline & \multicolumn{4}{|c|}{ All Countries } & \multicolumn{4}{|c|}{ Developed Countries } \\
\hline & Const. & $R X$ & $H M L$ & $\bar{R}^{2}$ & Const. & $R X$ & $H M L$ & $\bar{R}^{2}$ \\
\hline $\mathrm{P} 1$ & $\begin{array}{c}-0.13 \\
(-1.42)\end{array}$ & $\begin{array}{c}1.11 \\
(46.79)\end{array}$ & $\begin{array}{c}-0.49 \\
(-18.78)\end{array}$ & 90.42 & $\begin{array}{c}-0.13 \\
(-1.73)\end{array}$ & $\begin{array}{c}1.08 \\
(35.47)\end{array}$ & $\begin{array}{c}-0.48 \\
(-16.87)\end{array}$ & 92.46 \\
\hline $\mathrm{P} 2$ & $\begin{array}{c}-0.44 \\
(-3.07)\end{array}$ & $\begin{array}{c}1.01 \\
(23.75)\end{array}$ & $\begin{array}{c}-0.03 \\
(-0.83)\end{array}$ & 78.49 & $\begin{array}{c}-0.28 \\
(-2.77)\end{array}$ & $\begin{array}{c}0.99 \\
(36.53)\end{array}$ & $\begin{array}{c}0.00 \\
(0.14)\end{array}$ & 83.69 \\
\hline P3 & $\begin{array}{l}-0.31 \\
(-2.37)\end{array}$ & $\begin{array}{c}0.95 \\
(33.04)\end{array}$ & $\begin{array}{c}0.00 \\
(0.09)\end{array}$ & 75.82 & $\begin{array}{l}-0.20 \\
(-2.07)\end{array}$ & $\begin{array}{c}0.99 \\
(44.55)\end{array}$ & $\begin{array}{c}0.01 \\
(0.30)\end{array}$ & 82.72 \\
\hline P4 & $\begin{array}{l}-0.14 \\
(-1.23)\end{array}$ & $\begin{array}{c}0.97 \\
(34.27)\end{array}$ & $\begin{array}{c}0.02 \\
(0.53)\end{array}$ & 78.39 & $\begin{array}{l}-0.05 \\
(-0.46)\end{array}$ & $\begin{array}{c}0.95 \\
(28.16)\end{array}$ & $\begin{array}{c}0.02 \\
(0.73)\end{array}$ & 80.65 \\
\hline P5 & $\begin{array}{c}0.01 \\
(0.06)\end{array}$ & $\begin{array}{c}0.99 \\
(29.83)\end{array}$ & $\begin{array}{c}0.07 \\
(2.58)\end{array}$ & 79.65 & $\begin{array}{c}-0.14 \\
(-1.52)\end{array}$ & $\begin{array}{c}1.10 \\
(27.24)\end{array}$ & $\begin{array}{c}0.50 \\
(13.37)\end{array}$ & 91.77 \\
\hline P6 & $\begin{array}{c}-0.12 \\
(-1.11)\end{array}$ & $\begin{array}{c}1.12 \\
(34.67)\end{array}$ & $\begin{array}{c}0.50 \\
(14.72)\end{array}$ & 89.23 & & & & \\
\hline \multicolumn{9}{|c|}{ Panel B: Factor Prices } \\
\hline & $R X$ & $H M L$ & $\bar{R}^{2}$ & RMSE & $R X$ & $H M L$ & $\bar{R}^{2}$ & RMSE \\
\hline & $\begin{array}{c}0.28 \\
(1.29) \\
{[1.29]}\end{array}$ & $\begin{array}{c}0.91 \\
(3.88) \\
{[3.88]} \\
\end{array}$ & 70.74 & 4.30 & $\begin{array}{c}0.18 \\
(0.86) \\
{[0.86]} \\
\end{array}$ & $\begin{array}{c}0.59 \\
(3.05) \\
{[3.05]} \\
\end{array}$ & 79.69 & 2.10 \\
\hline
\end{tabular}


Table V. Different Estimation Methodologies

The table reports cross-sectional pricing results for the linear factor model based on the dollar risk factor $(R X)$ and the consumption factor in equities $(H M L)$. The test assets are six (five) equity portfolios from all (developed) countries sorted annually on year-overyear consumption growth based upon the fourth-quarter. Panel A reports the two-stage GMM estimates of SDF parameters and factor prices with second-stage GMM HAC $t$ statistics in parentheses. Panel B reports the GLS estimates of factor prices obtained by Fama and MacBeth (1973) cross-sectional regressions with Shanken (1992) corrected $t$ statistics in parentheses. Panel C reports the OLS estimates of factor prices obtained by Fama and MacBeth (1973) cross-sectional regressions with Shanken (1992) corrected $t$ statistics in parentheses. We do not include a constant in the second-stage regressions. The four variants of MSCI equity indices are (I) standard indices, (II) indices of small caps, (III) indices with net dividends, i.e. net total return indices reinvest dividends after the deduction of withholding taxes, and (IV) indices with gross dividends, i.e. gross total return indices reinvest as much as possible of a company's dividend distributions. The cross-sectional adjusted $\bar{R}^{2}$ statistics and the annualized root mean squared error (RMSE) are in \%. Returns are monthly and the sample period is January 1970 - December 2012.

\begin{tabular}{|c|c|c|c|c|c|c|c|c|}
\hline & \multicolumn{4}{|c|}{ All Countries } & \multicolumn{4}{|c|}{ Developed Countries } \\
\hline & $\mathrm{I}$ & II & III & IV & $\mathrm{I}$ & II & III & IV \\
\hline \multicolumn{9}{|c|}{ Panel A: GMM } \\
\hline & \multicolumn{8}{|c|}{ SDF Parameters } \\
\hline \multirow[t]{2}{*}{$R X$} & 0.01 & 0.02 & 0.02 & 0.02 & 0.01 & 0.02 & 0.02 & 0.02 \\
\hline & $(1.02)$ & $(1.42)$ & $(1.72)$ & $(1.84)$ & $(0.57)$ & $(1.17)$ & $(1.51)$ & $(1.53)$ \\
\hline \multirow[t]{3}{*}{$H M L$} & 0.04 & 0.05 & 0.04 & 0.03 & 0.03 & 0.06 & 0.03 & 0.03 \\
\hline & $(3.66)$ & $(3.37)$ & $(2.89)$ & $(2.43)$ & $(2.42)$ & $(3.35)$ & $(2.39)$ & $(2.39)$ \\
\hline & \multicolumn{8}{|c|}{ Factor Prices } \\
\hline \multirow[t]{2}{*}{$R X$} & 0.28 & 0.59 & 0.46 & 0.52 & 0.16 & 0.44 & 0.40 & 0.44 \\
\hline & $(1.06)$ & (1.19) & $(1.84)$ & (1.98) & $(0.65)$ & $(0.95)$ & (1.62) & $(1.80)$ \\
\hline \multirow[t]{2}{*}{$H M L$} & 0.85 & 0.98 & 0.72 & 0.56 & 0.61 & 0.83 & 0.60 & 0.60 \\
\hline & $(3.69)$ & $(2.78)$ & $(3.22)$ & $(2.51)$ & $(2.71)$ & $(2.84)$ & $(2.57)$ & $(2.69)$ \\
\hline $\bar{R}^{2}$ & 76.48 & 54.01 & 81.78 & 57.98 & 84.07 & 81.15 & 87.22 & 93.27 \\
\hline$R M S E$ & 4.31 & 7.86 & 3.18 & 4.51 & 2.14 & 3.29 & 1.88 & 1.35 \\
\hline \multicolumn{9}{|c|}{ Panel B: GLS } \\
\hline \multirow[t]{2}{*}{$R X$} & 0.29 & 0.47 & 0.48 & 0.54 & 0.18 & 0.38 & 0.38 & 0.44 \\
\hline & $(1.30)$ & $(1.23)$ & $(2.26)$ & $(2.42)$ & $(0.86)$ & $(1.05)$ & (1.81) & $(2.10)$ \\
\hline \multirow[t]{2}{*}{$H M L$} & 0.86 & 0.86 & 0.74 & 0.56 & 0.58 & 0.83 & 0.58 & 0.59 \\
\hline & $(3.69)$ & $(2.45)$ & (3.60) & $(2.56)$ & $(3.01)$ & $(3.26)$ & $(2.95)$ & $(3.07)$ \\
\hline$R M S E$ & 4.32 & 7.75 & 3.19 & 4.51 & 2.10 & 3.31 & 1.87 & 1.35 \\
\hline \multicolumn{9}{|c|}{ Panel C: OLS } \\
\hline \multirow[t]{2}{*}{$R X$} & 0.28 & 0.46 & 0.49 & 0.54 & 0.18 & 0.39 & 0.38 & 0.44 \\
\hline & (1.29) & (1.21) & $(2.27)$ & $(2.40)$ & $(0.86)$ & (1.07) & (1.81) & $(2.10)$ \\
\hline \multirow[t]{2}{*}{$H M L$} & 0.91 & 0.99 & 0.76 & 0.60 & 0.59 & 0.77 & 0.59 & 0.59 \\
\hline & (3.88) & $(2.74)$ & $(3.71)$ & $(2.71)$ & $(3.05)$ & $(2.96)$ & (2.99) & $(3.10)$ \\
\hline $\bar{R}^{2}$ & 70.74 & 45.22 & 77.23 & 47.57 & 79.69 & 75.10 & 83.07 & 91.04 \\
\hline$R M S E$ & 4.30 & 7.67 & 3.18 & 4.50 & 2.10 & 3.27 & 1.87 & 1.34 \\
\hline
\end{tabular}




\section{Table VI. Time Span Split}

The table reports cross-sectional pricing results for the linear factor model based on the dollar risk factor $(R X)$ and the consumption factor in equities $(H M L)$. The test assets are six equity portfolios from all countries sorted annually on year-over-year consumption growth based upon the fourth-quarter presented in Table I. Early sample covers the period January 1970 - May 2002. Late sample covers the period June 2002 - December 2012. Please see notes to Table IV for further details.

\begin{tabular}{|c|c|c|c|c|c|c|c|c|}
\hline \multicolumn{9}{|c|}{ Panel A: Factor Betas } \\
\hline & \multicolumn{4}{|c|}{ Early Sample } & \multicolumn{4}{|c|}{ Late Sample } \\
\hline & Const. & $R X$ & $H M L$ & $\bar{R}^{2}$ & Const. & $R X$ & $H M L$ & $\bar{R}^{2}$ \\
\hline $\mathrm{P} 1$ & $\begin{array}{c}-0.06 \\
(-0.53)\end{array}$ & $\begin{array}{c}1.14 \\
(35.10)\end{array}$ & $\begin{array}{c}-0.50 \\
(-17.84)\end{array}$ & 88.06 & $\begin{array}{c}-0.41 \\
(-3.24)\end{array}$ & $\begin{array}{c}1.06 \\
(37.23)\end{array}$ & $\begin{array}{c}-0.42 \\
(-13.47)\end{array}$ & 97.31 \\
\hline $\mathrm{P} 2$ & $\begin{array}{c}-0.45 \\
(-2.53)\end{array}$ & $\begin{array}{c}0.99 \\
(15.62)\end{array}$ & $\begin{array}{c}-0.02 \\
(-0.39)\end{array}$ & 71.31 & $\begin{array}{l}-0.30 \\
(-1.66)\end{array}$ & $\begin{array}{c}1.03 \\
(23.62)\end{array}$ & $\begin{array}{c}-0.15 \\
(-3.22)\end{array}$ & 93.20 \\
\hline P3 & $\begin{array}{c}-0.31 \\
(-1.90)\end{array}$ & $\begin{array}{c}0.93 \\
(22.61)\end{array}$ & $\begin{array}{c}0.02 \\
(0.60)\end{array}$ & 67.38 & $\begin{array}{c}-0.19 \\
(-1.35)\end{array}$ & $\begin{array}{c}0.97 \\
(33.86)\end{array}$ & $\begin{array}{l}-0.12 \\
(-2.66)\end{array}$ & 94.23 \\
\hline P4 & $\begin{array}{l}-0.12 \\
(-0.81)\end{array}$ & $\begin{array}{c}0.93 \\
(26.95)\end{array}$ & $\begin{array}{c}0.01 \\
(0.44)\end{array}$ & 69.92 & $\begin{array}{l}-0.26 \\
(-1.94)\end{array}$ & $\begin{array}{c}1.03 \\
(33.40)\end{array}$ & $\begin{array}{c}0.03 \\
(0.93)\end{array}$ & 94.29 \\
\hline P5 & $\begin{array}{c}-0.03 \\
(-0.20)\end{array}$ & $\begin{array}{c}0.96 \\
(21.83)\end{array}$ & $\begin{array}{c}0.05 \\
(1.95)\end{array}$ & 72.62 & $\begin{array}{c}0.03 \\
(0.15)\end{array}$ & $\begin{array}{c}1.04 \\
(24.11)\end{array}$ & $\begin{array}{c}0.15 \\
(3.44)\end{array}$ & 92.79 \\
\hline P6 & $\begin{array}{c}-0.05 \\
(-0.37)\end{array}$ & $\begin{array}{c}1.16 \\
(25.97)\end{array}$ & $\begin{array}{c}0.49 \\
(14.19)\end{array}$ & 86.77 & $\begin{array}{c}-0.41 \\
(-2.83)\end{array}$ & $\begin{array}{c}1.05 \\
(29.46)\end{array}$ & $\begin{array}{c}0.59 \\
(16.84)\end{array}$ & 96.91 \\
\hline \multicolumn{9}{|c|}{ Panel B: Factor Prices } \\
\hline & $R X$ & $H M L$ & $\bar{R}^{2}$ & RMSE & $R X$ & $H M L$ & $\bar{R}^{2}$ & RMSE \\
\hline & $\begin{array}{c}0.17 \\
(0.76) \\
{[0.76]}\end{array}$ & $\begin{array}{c}0.75 \\
(2.58) \\
{[2.58]}\end{array}$ & 56.33 & 4.77 & $\begin{array}{c}0.62 \\
(1.14) \\
{[1.14]}\end{array}$ & $\begin{array}{c}1.28 \\
(3.82) \\
{[3.84]}\end{array}$ & 84.94 & 4.34 \\
\hline
\end{tabular}


Table VII. Alphabetic Country Split

The table reports cross-sectional pricing results for the linear factor model based on the dollar risk factor $(R X)$ and the consumption factor in equities $(H M L)$. The test assets are five equity portfolios sorted annually on year-over-year consumption growth based upon the fourth-quarter. Group I uses the first half of all countries sorted alphabetically. Group II uses the second half of all countries sorted alphabetically. Please see notes to Table IV for further details.

\begin{tabular}{|c|c|c|c|c|c|c|c|c|}
\hline \multicolumn{9}{|c|}{ Panel A: Factor Betas } \\
\hline & \multicolumn{4}{|c|}{ Group I } & \multicolumn{4}{|c|}{ Group II } \\
\hline & Const. & $R X$ & $H M L$ & $\bar{R}^{2}$ & Const. & $R X$ & $H M L$ & $\bar{R}^{2}$ \\
\hline $\mathrm{P} 1$ & $\begin{array}{c}-0.12 \\
(-1.18)\end{array}$ & $\begin{array}{c}1.08 \\
(32.47)\end{array}$ & $\begin{array}{c}-0.47 \\
(-19.89)\end{array}$ & 87.16 & $\begin{array}{c}-0.15 \\
(-1.60)\end{array}$ & $\begin{array}{c}1.10 \\
(46.61)\end{array}$ & $\begin{array}{c}-0.46 \\
(-17.87)\end{array}$ & 90.06 \\
\hline $\mathrm{P} 2$ & $\begin{array}{c}-0.44 \\
(-2.72)\end{array}$ & $\begin{array}{c}0.99 \\
(24.96)\end{array}$ & $\begin{array}{c}-0.10 \\
(-2.86)\end{array}$ & 70.56 & $\begin{array}{c}-0.51 \\
(-3.01)\end{array}$ & $\begin{array}{c}1.01 \\
(16.41)\end{array}$ & $\begin{array}{c}-0.07 \\
(-2.14)\end{array}$ & 69.65 \\
\hline P3 & $\begin{array}{c}-0.15 \\
(-1.08)\end{array}$ & $\begin{array}{c}0.99 \\
(29.21)\end{array}$ & $\begin{array}{c}0.02 \\
(0.79)\end{array}$ & 72.74 & $\begin{array}{c}-0.22 \\
(-1.32)\end{array}$ & $\begin{array}{c}0.94 \\
(26.90)\end{array}$ & $\begin{array}{c}0.00 \\
(0.14)\end{array}$ & 67.54 \\
\hline P4 & $\begin{array}{c}-0.14 \\
(-0.99)\end{array}$ & $\begin{array}{c}0.98 \\
(26.76)\end{array}$ & $\begin{array}{c}0.04 \\
(1.37)\end{array}$ & 69.17 & $\begin{array}{c}-0.03 \\
(-0.20)\end{array}$ & $\begin{array}{c}0.94 \\
(31.24)\end{array}$ & $\begin{array}{c}0.01 \\
(0.50)\end{array}$ & 71.21 \\
\hline P5 & $\begin{array}{c}-0.14 \\
(-1.29) \\
\end{array}$ & $\begin{array}{c}1.08 \\
(31.22) \\
\end{array}$ & $\begin{array}{c}0.52 \\
(21.33) \\
\end{array}$ & 87.93 & $\begin{array}{c}-0.13 \\
(-1.31) \\
\end{array}$ & $\begin{array}{c}1.10 \\
(38.36) \\
\end{array}$ & $\begin{array}{c}0.53 \\
(22.96) \\
\end{array}$ & 89.91 \\
\hline \multicolumn{9}{|c|}{ Panel B: Factor Prices } \\
\hline & $R X$ & $H M L$ & $\bar{R}^{2}$ & RMSE & $R X$ & $H M L$ & $\bar{R}^{2}$ & $R M S E$ \\
\hline & $\begin{array}{c}0.19 \\
(0.85) \\
{[0.88]} \\
\end{array}$ & $\begin{array}{c}0.38 \\
(1.54) \\
{[1.54]} \\
\end{array}$ & 33.50 & 3.37 & $\begin{array}{c}0.28 \\
(1.23) \\
{[1.23]} \\
\end{array}$ & $\begin{array}{c}1.30 \\
(4.75) \\
{[4.75]} \\
\end{array}$ & 82.31 & 4.29 \\
\hline
\end{tabular}


Table VIII. Country Level Results

The table reports cross-sectional pricing results for the linear factor model based on the dollar risk factor $(R X)$ and the consumption factor in equities $(H M L)$. The test assets are excess equity returns to individual MSCI equity index returns from all 47 countries (left panel) and from 25 developed countries (right panel). Conditional betas are computed using (I) individual countries' consumption growth measured in USD, (II) GDP-weighted countries' consumption growth measured in USD, (III) individual countries' consumption growth measured in national currency, and (IV) GDP-weighted countries' consumption growth measured in national currency. Reported are coefficient estimates of factor risk prices obtained by Fama and MacBeth (1973) cross-sectional regressions. Panel A shows coefficient estimates of factor risk prices obtained by cross-sectional regressions without a constant. Panel B shows coefficient estimates of factor risk prices obtained by crosssectional regressions including a constant. Fama and MacBeth (1973) $t$-statistics are reported in parentheses. The cross-sectional adjusted $\bar{R}^{2}$ statistics and the annualized root mean squared error $(R M S E)$ are in $\%$. Returns are annual and the sample period is 1970 - 2012.

\begin{tabular}{lcccccccc}
\hline \hline & \multicolumn{9}{c}{ All Countries } & \multicolumn{5}{c}{ Developed Countries } \\
\hline & I & II & III & IV & I & II & III & IV \\
\hline$R X$ & -0.80 & -2.04 & -0.91 & -2.00 & -0.13 & -1.24 & 0.16 & -0.97 \\
& $(-0.23)$ & $(-0.59)$ & $(-0.26)$ & $(-0.57)$ & $(-0.04)$ & $(-0.33)$ & $(0.05)$ & $(-0.26)$ \\
$H M L$ & 7.98 & 12.03 & 8.15 & 10.11 & 9.42 & 12.41 & 10.11 & 10.17 \\
& $(2.13)$ & $(2.34)$ & $(2.14)$ & $(1.79)$ & $(2.49)$ & $(2.17)$ & $(2.57)$ & $(1.69)$ \\
$\bar{R}^{2}$ & 10.87 & 16.79 & 9.98 & 14.27 & 45.63 & 54.23 & 33.54 & 51.14 \\
$R M S E$ & 0.70 & 0.68 & 0.71 & 0.69 & 0.16 & 0.15 & 0.18 & 0.15 \\
\hline & \multicolumn{9}{c}{ Panel B: Unrestricted Beta Representation } & & \\
\hline Const. & 0.04 & 0.08 & 0.06 & 0.09 & 0.03 & 0.07 & 0.04 & 0.06 \\
& $(1.37)$ & $(2.69)$ & $(2.38)$ & $(2.90)$ & $(0.88)$ & $(1.48)$ & $(1.35)$ & $(1.52)$ \\
$R X$ & -2.74 & -7.77 & -4.82 & -8.05 & -2.44 & -6.63 & -2.93 & -6.23 \\
& $(-0.71)$ & $(-1.96)$ & $(-1.18)$ & $(-1.93)$ & $(-0.59)$ & $(-1.11)$ & $(-0.75)$ & $(-1.07)$ \\
$H M L$ & 8.14 & 11.96 & 8.16 & 10.17 & 9.30 & 11.30 & 9.87 & 9.34 \\
& $(2.19)$ & $(2.34)$ & $(2.12)$ & $(1.78)$ & $(2.49)$ & $(1.82)$ & $(2.55)$ & $(1.45)$ \\
$\bar{R}^{2}$ & 31.29 & 41.58 & 34.19 & 41.11 & 33.20 & 49.27 & 39.69 & 51.26 \\
$R M S E$ & 0.61 & 0.56 & 0.60 & 0.57 & 0.18 & 0.16 & 0.17 & 0.15 \\
\hline \hline
\end{tabular}


Table IX. Portfolios Sorted on HML-Betas

The table reports mean returns, standard deviations, and Sharpe ratios (SR) for equity portfolios sorted on $H M L$ betas. Equities are sorted into portfolios according to their $H M L$ beta in a 36-month moving window time-series regression of individual equity index excess returns on a constant and $H M L$. The first portfolio contains equity indices with the lowest $H M L$ betas. The last portfolio contains equity indices with the highest $H M L$ betas. All returns are excess returns in USD. The upper panel shows six portfolios from all countries; the lower panel shows five portfolios from developed countries. For each portfolio, the table also reports the average pre-formation $H M L$ beta and the postformation $H M L$ beta obtained by regressing realized log excess portfolio returns on a constant, $R X$ and $H M L$. Newey and West (1987) $t$-statistics with optimal lag length are in parentheses. Returns are monthly and the sample period is January 1970 - December 2012.

\begin{tabular}{|c|c|c|c|c|c|c|c|c|}
\hline \multicolumn{9}{|c|}{ All Countries } \\
\hline & P1 & $\mathrm{P} 2$ & P3 & P4 & $\mathrm{P} 5$ & P6 & $R X$ & HML \\
\hline \multicolumn{9}{|c|}{ Excess Returns } \\
\hline Mean & -0.18 & 0.07 & 0.18 & 0.20 & 0.31 & 0.43 & 0.17 & 0.60 \\
\hline Std. & 1.39 & 0.94 & 0.98 & 1.00 & 1.03 & 1.30 & 0.96 & 1.35 \\
\hline SR & -0.13 & 0.08 & 0.18 & 0.20 & 0.30 & 0.33 & 0.18 & 0.45 \\
\hline \multicolumn{9}{|c|}{ Pre-Formation $H M L$ Beta } \\
\hline Mean & -0.44 & -0.17 & -0.05 & 0.07 & 0.20 & 0.54 & & \\
\hline Std. & 0.36 & 0.29 & 0.28 & 0.29 & 0.31 & 0.43 & & \\
\hline \multicolumn{9}{|c|}{ Post-Formation $H M L$ Beta } \\
\hline $\begin{array}{l}\text { Estimate } \\
t \text {-stat. }\end{array}$ & $\begin{array}{c}-0.57 \\
(-16.29)\end{array}$ & $\begin{array}{c}-0.11 \\
(-4.90)\end{array}$ & $\begin{array}{c}0.06 \\
(1.76)\end{array}$ & $\begin{array}{c}0.08 \\
(2.33)\end{array}$ & $\begin{array}{c}0.10 \\
(3.92)\end{array}$ & $\begin{array}{c}0.43 \\
(13.12)\end{array}$ & & \\
\hline \multicolumn{9}{|c|}{ Developed Countries } \\
\hline & $\mathrm{P} 1$ & $\mathrm{P} 2$ & P3 & P4 & P5 & $R X$ & $H M L$ & \\
\hline \multicolumn{9}{|c|}{ Excess Returns } \\
\hline Mean & -0.18 & 0.09 & 0.15 & 0.26 & 0.28 & 0.12 & 0.47 & \\
\hline Std. & 1.05 & 0.88 & 0.93 & 1.03 & 1.19 & 0.92 & 0.86 & \\
\hline SR & -0.18 & 0.10 & 0.16 & 0.25 & 0.24 & 0.13 & 0.55 & \\
\hline \multicolumn{9}{|c|}{ Pre-Formation $H M L$ Beta } \\
\hline Mean & -0.42 & -0.12 & 0.05 & 0.19 & 0.51 & & & \\
\hline Std. & 0.33 & 0.28 & 0.26 & 0.28 & 0.35 & & & \\
\hline \multicolumn{9}{|c|}{ Post-Formation $H M L$ Beta } \\
\hline $\begin{array}{l}\text { Estimate } \\
t \text {-stat }\end{array}$ & $\begin{array}{c}-0.55 \\
(-16.15)\end{array}$ & $\begin{array}{c}-0.09 \\
(-289)\end{array}$ & $\begin{array}{l}0.14 \\
(3.38)\end{array}$ & $\begin{array}{l}0.05 \\
(137)\end{array}$ & $\begin{array}{c}0.45 \\
(13.59)\end{array}$ & & & \\
\hline
\end{tabular}


Table X. World Consumption Dispersion

The table reports cross-sectional pricing results for the linear factor model based on the dollar risk factor $(R X)$ and world consumption dispersion risk factor $(W C D)$. The $W C D$ factor is obtained as innovations in the $\operatorname{AR}(2)$ process for cross-sectional variance in year-over-year consumption growth based upon the fourth-quarter. The test assets are six (five) equity portfolios from all (developed) countries sorted annually on year-over-year consumption growth based upon the fourth-quarter presented in Table I. Panel A shows OLS estimates of betas with Newey and West (1987) $t$-statistics with optimal lag length in parentheses and adjusted $\bar{R}^{2}$ statistics in \%. Panel B shows coefficient estimates of factor risk prices obtained by Fama and MacBeth (1973) cross-sectional regressions. We do not include a constant in the second-stage regressions. Shanken (1992) corrected $t$ statistics are reported in parentheses and the Fama and MacBeth (1973) $t$-statistics appear in square brackets. The cross-sectional adjusted $\bar{R}^{2}$ statistics and the annualized root mean squared error (RMSE) are in \%. Returns are annual and the sample period is 1970 2012.

\begin{tabular}{|c|c|c|c|c|c|c|c|c|}
\hline \multicolumn{9}{|c|}{ Panel A: Factor Betas } \\
\hline & \multicolumn{4}{|c|}{ All Countries } & \multicolumn{4}{|c|}{ Developed Countries } \\
\hline & Const. & $R X$ & $W C D$ & $\bar{R}^{2}$ & Const. & $R X$ & $W C D$ & $\bar{R}^{2}$ \\
\hline P1 & $\begin{array}{l}-11.16 \\
(-3.93)\end{array}$ & $\begin{array}{c}1.38 \\
(12.19)\end{array}$ & $\begin{array}{c}6.23 \\
(0.77)\end{array}$ & 80.15 & $\begin{array}{c}-8.60 \\
(-3.64)\end{array}$ & $\begin{array}{c}1.38 \\
(7.72)\end{array}$ & $\begin{array}{c}8.96 \\
(1.93)\end{array}$ & 83.29 \\
\hline $\mathrm{P} 2$ & $\begin{array}{l}-7.07 \\
(-2.47)\end{array}$ & $\begin{array}{c}1.04 \\
(7.14)\end{array}$ & $\begin{array}{c}4.89 \\
(0.74)\end{array}$ & 70.65 & $\begin{array}{l}-4.05 \\
(-1.85)\end{array}$ & $\begin{array}{c}1.03 \\
(5.49)\end{array}$ & $\begin{array}{c}6.36 \\
(1.92)\end{array}$ & 78.41 \\
\hline P3 & $\begin{array}{l}-5.02 \\
(-2.83)\end{array}$ & $\begin{array}{c}1.01 \\
(11.03)\end{array}$ & $\begin{array}{c}0.49 \\
(0.11)\end{array}$ & 80.75 & $\begin{array}{l}-4.40 \\
(-2.47)\end{array}$ & $\begin{array}{c}1.13 \\
(16.48)\end{array}$ & $\begin{array}{c}5.48 \\
(1.54)\end{array}$ & 87.43 \\
\hline P4 & $\begin{array}{l}-3.15 \\
(-1.50)\end{array}$ & $\begin{array}{c}0.99 \\
(11.07)\end{array}$ & $\begin{array}{l}-0.29 \\
(-0.07)\end{array}$ & 82.55 & $\begin{array}{l}-1.82 \\
(-1.21)\end{array}$ & $\begin{array}{c}0.96 \\
(16.88)\end{array}$ & $\begin{array}{c}1.09 \\
(0.46)\end{array}$ & 83.23 \\
\hline P5 & $\begin{array}{c}-1.38 \\
(-0.74)\end{array}$ & $\begin{array}{c}1.05 \\
(8.08)\end{array}$ & $\begin{array}{c}7.87 \\
(1.38)\end{array}$ & 80.54 & $\begin{array}{l}-2.73 \\
(-0.61)\end{array}$ & $\begin{array}{c}1.48 \\
(4.12)\end{array}$ & $\begin{array}{c}-8.80 \\
(-1.18)\end{array}$ & 72.59 \\
\hline P6 & $\begin{array}{c}1.19 \\
(0.45) \\
\end{array}$ & $\begin{array}{c}1.17 \\
(6.87) \\
\end{array}$ & $\begin{array}{l}-12.38 \\
(-1.94)\end{array}$ & 78.77 & & & & \\
\hline \multicolumn{9}{|c|}{ Panel B: Factor Prices } \\
\hline & $R X$ & $W C D$ & $\bar{R}^{2}$ & $R M S E$ & $R X$ & $W C D$ & $\bar{R}^{2}$ & RMSE \\
\hline & $\begin{array}{c}2.11 \\
(0.54) \\
{[0.56]}\end{array}$ & $\begin{array}{c}-0.37 \\
(-1.99) \\
{[-3.07]}\end{array}$ & 25.92 & 6.92 & $\begin{array}{c}1.07 \\
(0.28) \\
{[0.30]}\end{array}$ & $\begin{array}{c}-0.28 \\
(-1.40) \\
{[-1.90]}\end{array}$ & 58.11 & 2.67 \\
\hline
\end{tabular}


Table XI. HML and World Consumption Dispersion

The table reports cross-sectional pricing results for the linear factor model based on the dollar risk factor $(R X)$, the global consumption factor in equities $(H M L)$, and world consumption dispersion risk factor $(W C D)$. Please see notes to Table X for further details.

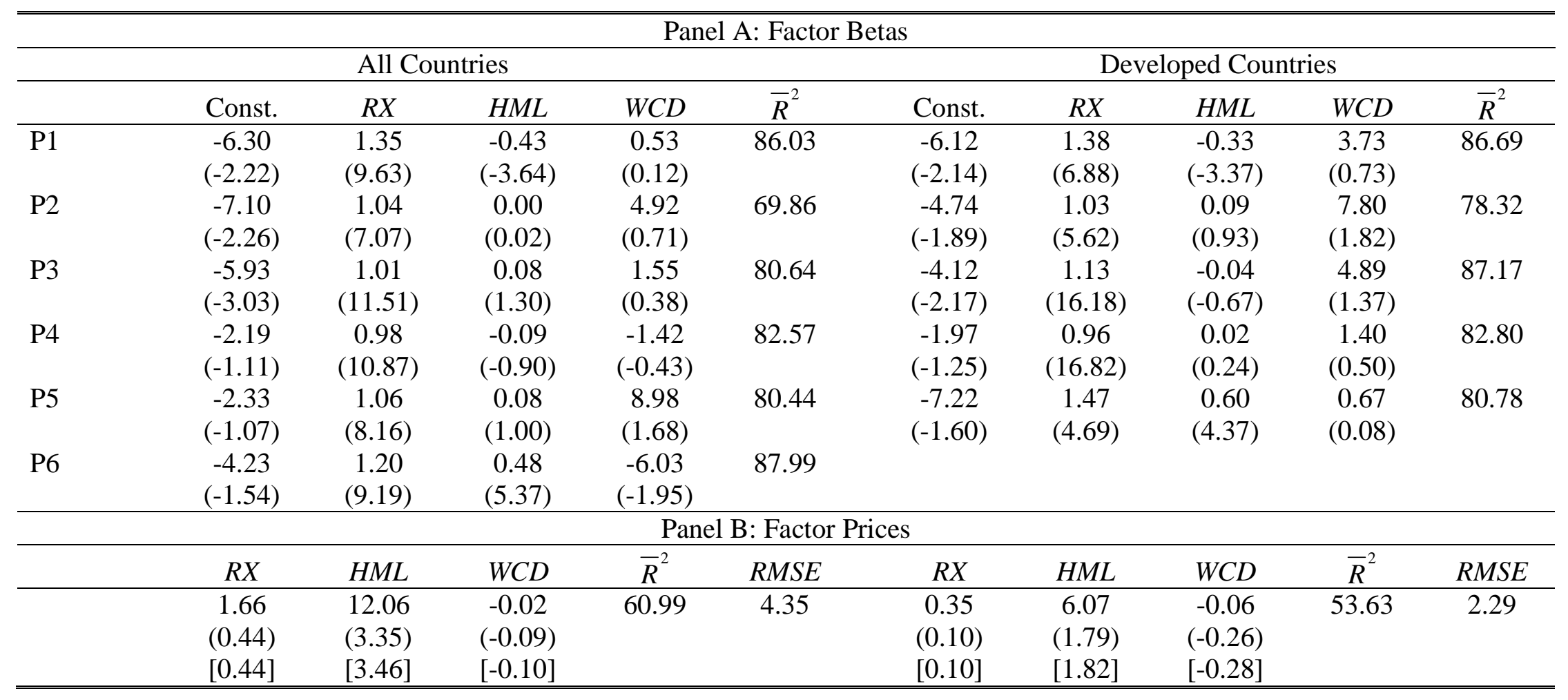


Table XII. Factor Mimicking World Consumption Dispersion

The table reports cross-sectional pricing results for the linear factor model based on the dollar risk factor $(R X)$ and the factor mimicking world consumption dispersion $(F W C D)$. The test assets are six (five) equity portfolios from all (developed) countries sorted annually on year-over-year consumption growth based upon the fourth-quarter presented in Table I. Panel A shows OLS estimates of betas with Newey and West (1987) $t$ statistics with optimal lag length in parentheses in parentheses and adjusted $\bar{R}^{2}$ statistics in \%. Panel B shows coefficient estimates of factor risk prices obtained by Fama and MacBeth (1973) cross-sectional regressions. We do not include a constant in the secondstage regressions. Shanken (1992) corrected $t$-statistics are reported in parentheses and the Fama and MacBeth (1973) $t$-statistics appear in square brackets. The cross-sectional adjusted $\bar{R}^{2}$ statistics and the annualized root mean squared error (RMSE) are in \%. Returns are annual and the sample period is $1970-2012$.

\begin{tabular}{|c|c|c|c|c|c|c|c|c|}
\hline \multicolumn{9}{|c|}{ Panel A: Factor Betas } \\
\hline & \multicolumn{4}{|c|}{ All Countries } & \multicolumn{4}{|c|}{ Developed Countries } \\
\hline & Const. & $R X$ & $F W C D$ & $\bar{R}^{2}$ & Const. & $R X$ & $F W C D$ & $\bar{R}^{2}$ \\
\hline \multirow[t]{2}{*}{ P1 } & -9.77 & 1.50 & 0.48 & 81.12 & -9.36 & 1.30 & 0.25 & 79.07 \\
\hline & $(-3.23)$ & (11.38) & $(2.27)$ & & $(-2.84)$ & $(6.64)$ & $(1.05)$ & \\
\hline \multirow[t]{2}{*}{$\mathrm{P} 2$} & -5.91 & 1.15 & 0.40 & 71.76 & -4.56 & 0.95 & 0.17 & 70.76 \\
\hline & $(-2.20)$ & (7.07) & $(1.88)$ & & $(-1.59)$ & (4.59) & $(0.75)$ & \\
\hline \multirow[t]{2}{*}{ P3 } & -5.04 & 1.00 & -0.01 & 80.75 & -5.68 & 0.98 & -0.07 & 80.09 \\
\hline & $(-2.76)$ & (8.97) & $(-0.05)$ & & $(-2.44)$ & $(8.54)$ & $(-0.31)$ & \\
\hline \multirow[t]{2}{*}{ P4 } & -3.42 & 0.96 & -0.10 & 82.64 & -2.58 & 0.90 & 0.11 & 78.06 \\
\hline & $(-1.64)$ & $(9.43)$ & $(-0.47)$ & & $(-1.44)$ & (10.08) & $(0.57)$ & \\
\hline \multirow[t]{2}{*}{ P5 } & 0.62 & 1.24 & 0.70 & 84.33 & -5.59 & 1.18 & -0.48 & 64.82 \\
\hline & $(0.36)$ & $(10.08)$ & $(4.46)$ & & $(-1.06)$ & $(3.31)$ & $(-1.13)$ & \\
\hline \multirow[t]{2}{*}{ P6 } & -1.81 & 0.89 & -1.04 & 84.60 & & & & \\
\hline & $(-0.71)$ & $(5.26)$ & $(-4.74)$ & & & & & \\
\hline \multicolumn{9}{|c|}{ Panel B: Factor Prices } \\
\hline & $R X$ & $F W C D$ & $\bar{R}^{2}$ & RMSE & $R X$ & $F W C D$ & $\bar{R}^{2}$ & $R M S E$ \\
\hline & 2.01 & -4.66 & 20.84 & 7.15 & 0.49 & -6.16 & 36.88 & 3.28 \\
\hline & $(0.53)$ & $(-2.55)$ & & & $(0.12)$ & $(-1.29)$ & & \\
\hline & {$[0.54]$} & {$[-2.60]$} & & & {$[0.12]$} & {$[-1.57]$} & & \\
\hline
\end{tabular}



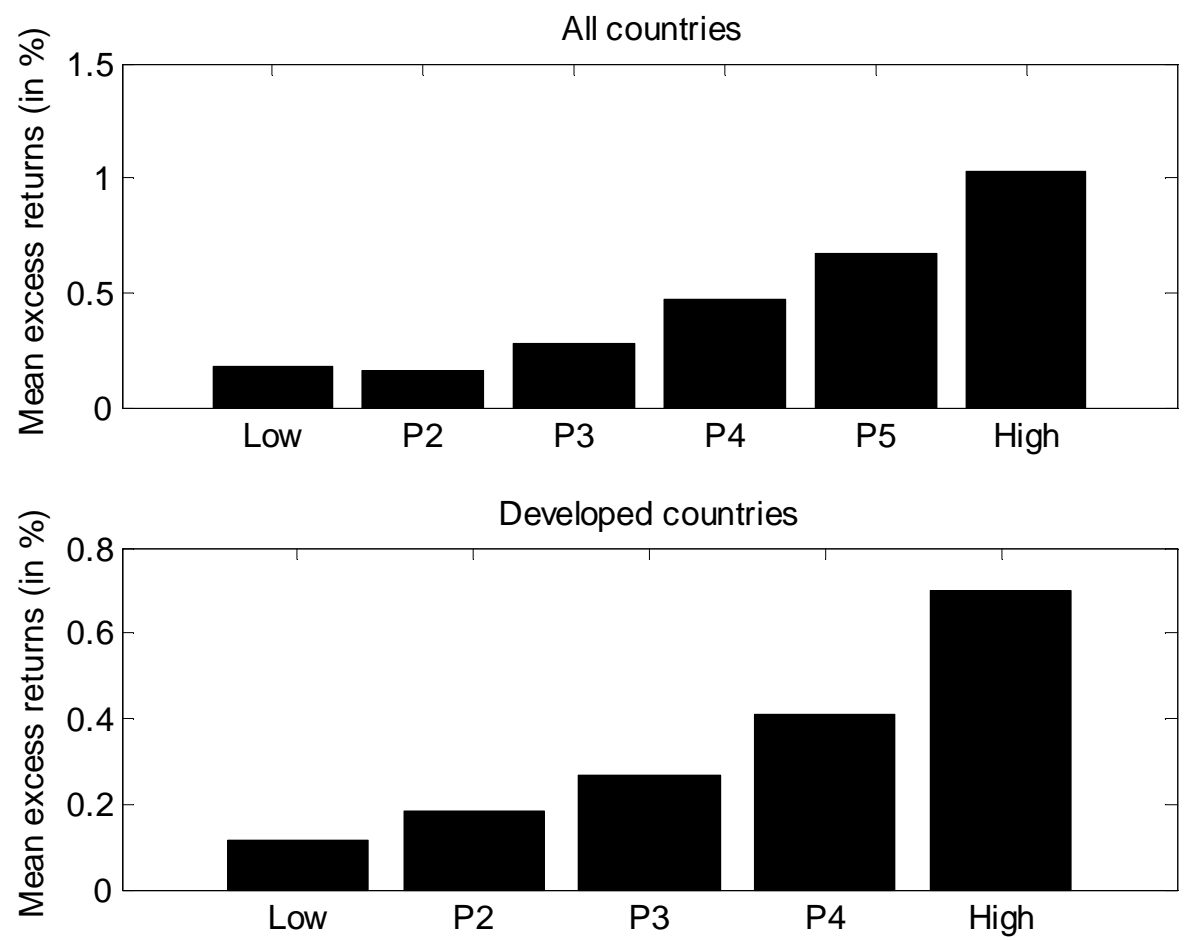

Figure 1. International Equity Portfolios. The figure shows monthly average excess returns for equity portfolios sorted annually on year-over-year consumption growth based upon the fourth-quarter. The first portfolio contains equity indices with the lowest consumption growth rates. The last portfolio contains equity indices with the highest consumption growth rates. All returns are excess returns in USD. The upper panel shows six portfolios from all countries; the lower panel shows five portfolios from developed countries. Returns are monthly and the sample period is January 1970 - December 2012. 


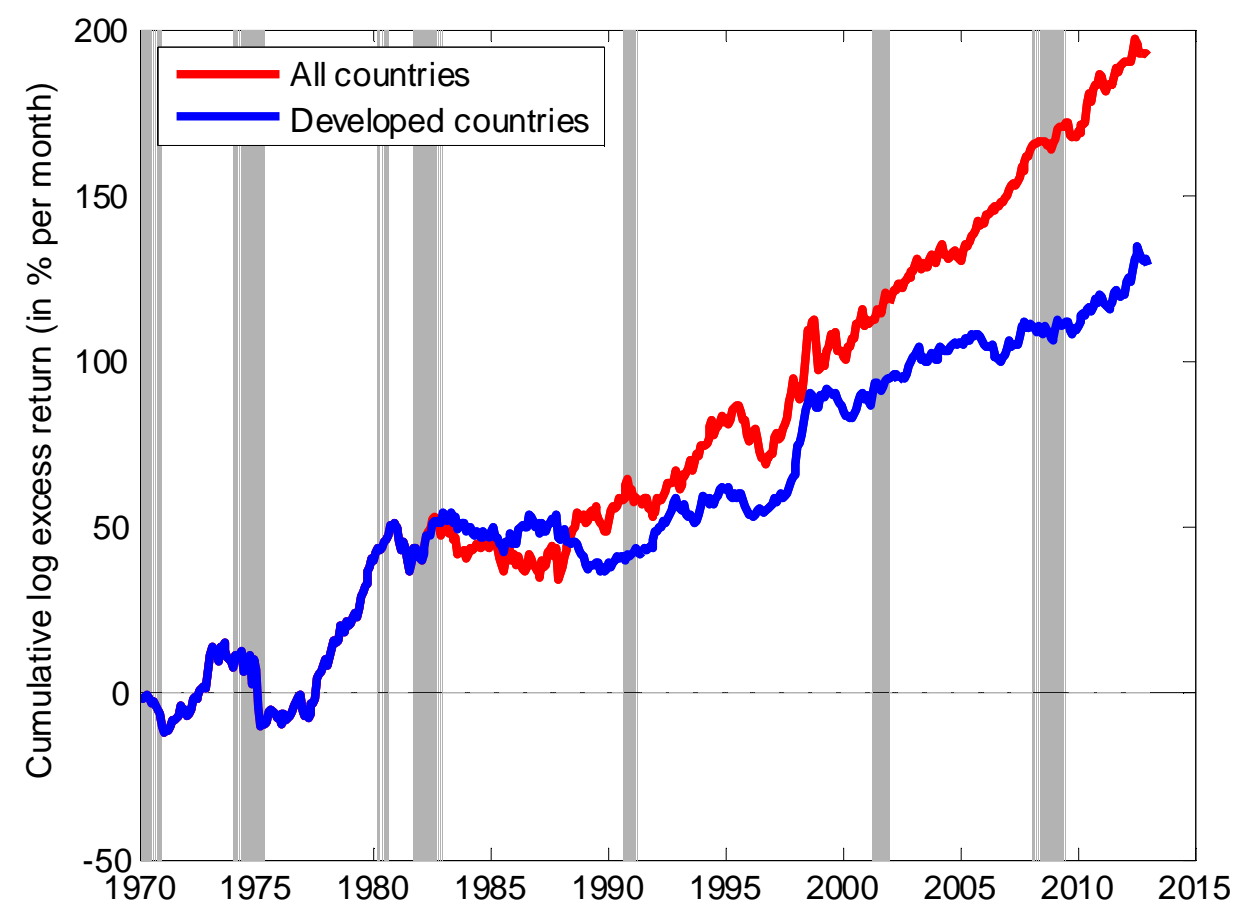

Figure 2. HML Factor in Equities. The figure shows cumulative log excess returns of the global consumption factor in equities which is equivalent to a high-minus-low $(H M L)$ strategy with a long position in markets with high year-over-year consumption growth rates based upon the fourth quarter and a short position in markets with low year-overyear consumption growth rates based upon the fourth quarter. The red line corresponds to the $H M L$ factor in all countries, while the blue line gives the $H M L$ factor in a subsample of developed countries. Shaded areas in the figure correspond to NBER recessions. Returns are monthly and the sample period is January 1970 - December 2012. 


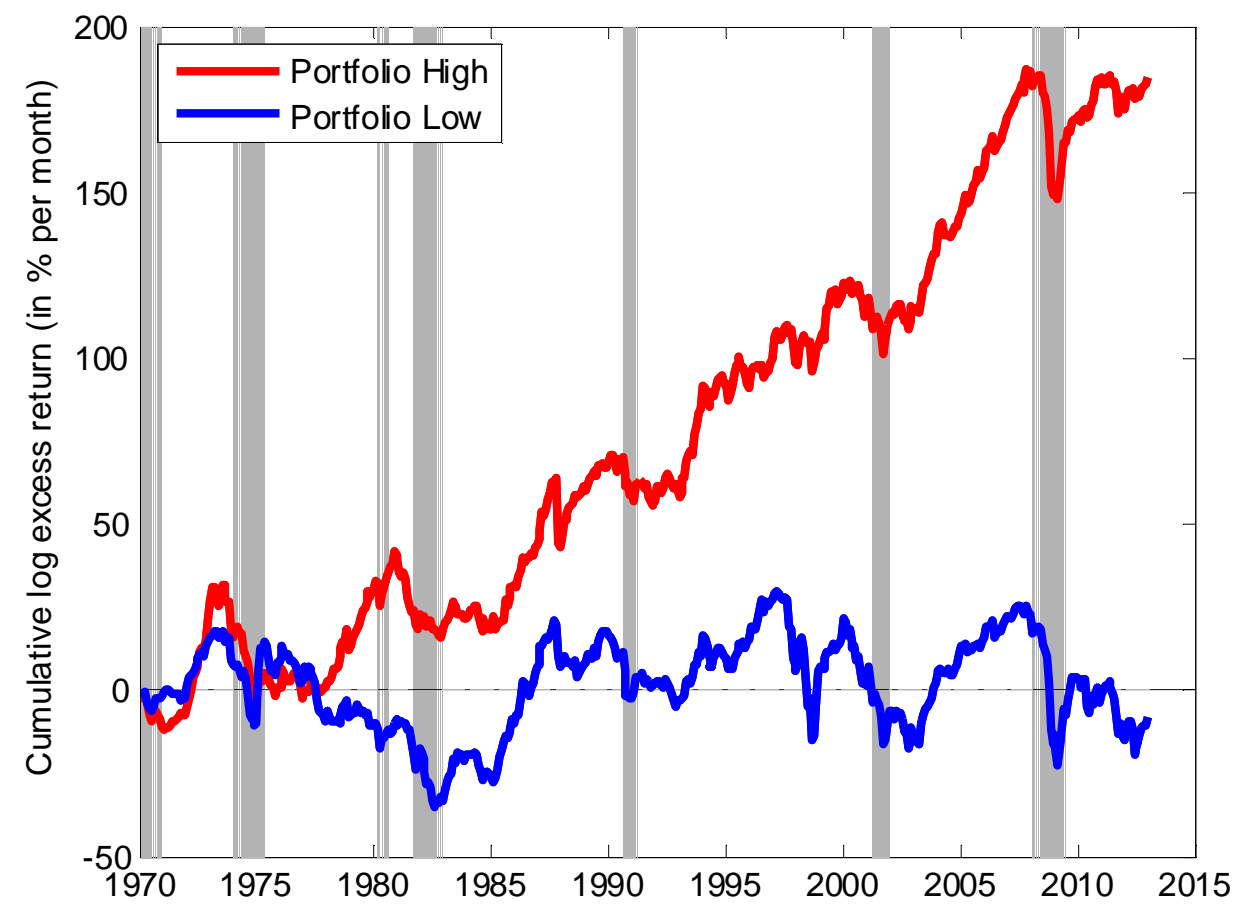

Figure 3A. High versus Low Consumption Growth Portfolios: All Countries. The figure shows cumulative log excess returns on the portfolio with the highest year-overyear consumption growth based upon the fourth-quarter (red) against the portfolio with the lowest year-over-year consumption growth based upon the fourth-quarter (blue) for all countries. Shaded areas in the figure correspond to NBER recessions. Returns are monthly and the sample period is January 1970 - December 2012. 


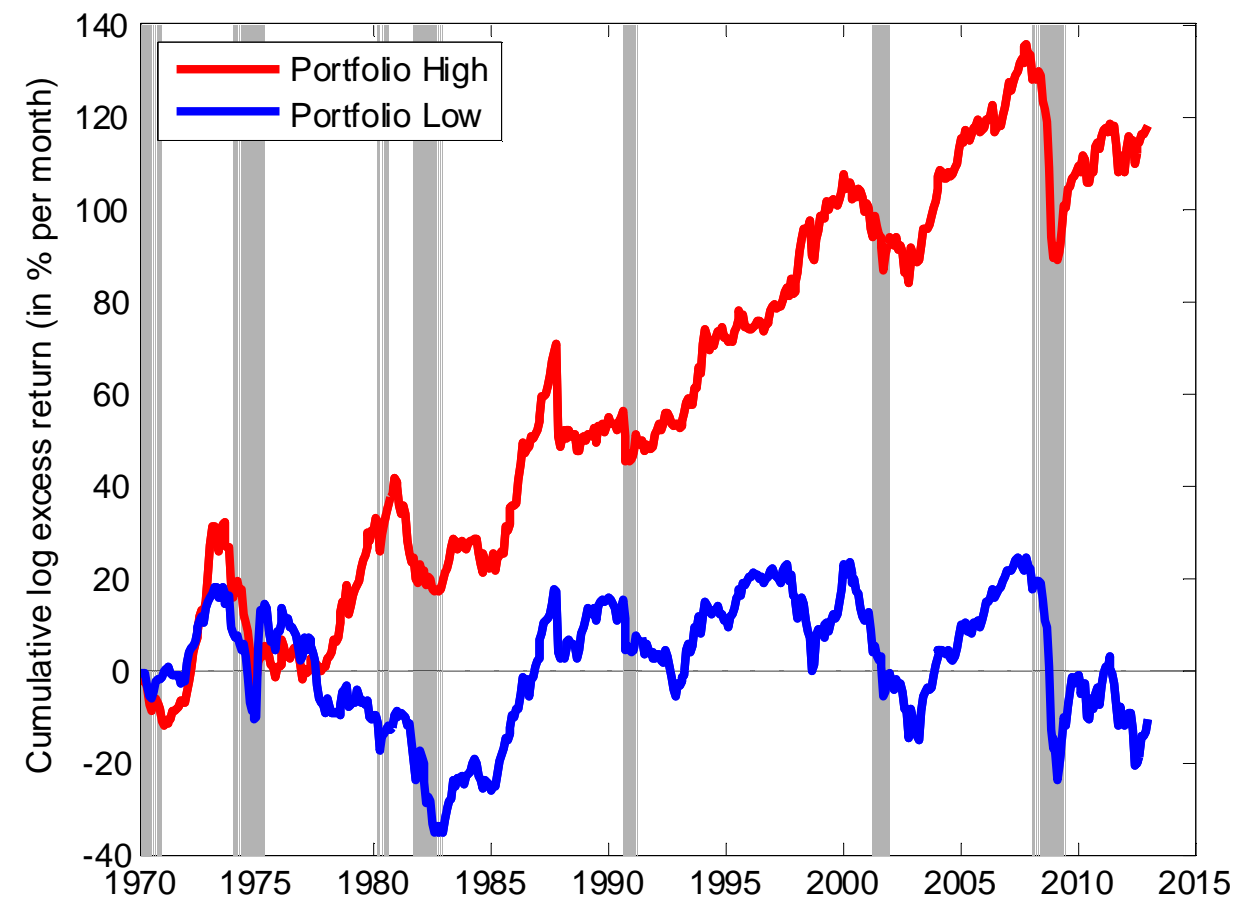

Figure 3B. High versus Low Consumption Growth Portfolios: Developed Countries. The figure shows cumulative log excess returns on the portfolio with the highest yearover-year consumption growth based upon the fourth-quarter (red) against the portfolio with the lowest year-over-year consumption growth based upon the fourth-quarter (blue) for a subsample of developed countries. Shaded areas in the figure correspond to NBER recessions. Returns are monthly and the sample period is January 1970 - December 2012. 


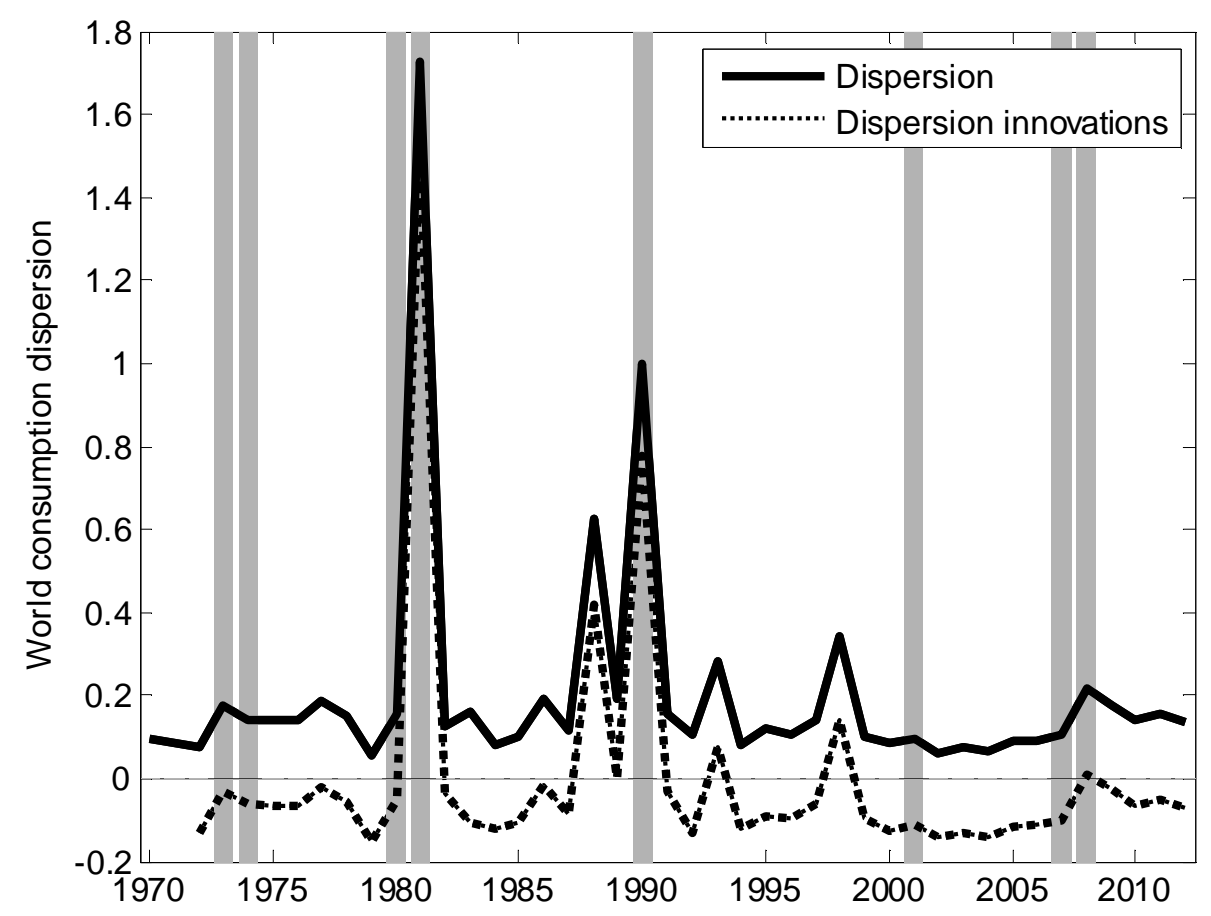

Figure 4. World Consumption Dispersion. The figure shows a time-series plot of world consumption dispersion (solid black line) and dispersion innovations (dotted black line). The world consumption dispersion is computed as cross-sectional variance in countries' year-over-year consumption growth rates based upon the fourth quarter. The innovations are obtained as the residuals from an $\mathrm{AR}(2)$ process for world consumption dispersion. Both series are multiplied by 100 . Shaded areas in the figure correspond to NBER recessions. The data are annual and the sample period is $1970-2012$. 